\title{
Simple versus complex degenerative mitral valve disease
}

Hoda Javadikasgari, MD, ${ }^{\mathrm{a}}$ Tomislav Mihaljevic, MD, ${ }^{\mathrm{a}}$ Rakesh M. Suri, MD, DPhil,

Lars G. Svensson, MD, PhD, ${ }^{\mathrm{a}}$ Jose L. Navia, MD, ${ }^{\mathrm{a}}$ Robert Z. Wang, MD, ${ }^{\mathrm{a}}$ Bassman Tappuni, MD, ${ }^{\mathrm{a}}$

Ashley M. Lowry, MS, ${ }^{b}$ Kenneth R. McCurry, MD, ${ }^{a}$ Eugene H. Blackstone, MD, ${ }^{\mathrm{a}, \mathrm{b}}$ Milind Y. Desai, MD,

Stephanie L. Mick, MD, ${ }^{a}$ and A. Marc Gillinov, MD ${ }^{\mathrm{a}}$

\section{ABSTRACT}

Objectives: At a center where surgeons favor mitral valve (MV) repair for all subsets of leaflet prolapse, we compared results of patients undergoing repair for simple versus complex degenerative MV disease.

Methods: From January 1985 to January 2016, 6153 patients underwent primary isolated MV repair for degenerative disease, 3101 patients underwent primary isolated MV repair for simple disease (posterior prolapse), and 3052 patients underwent primary isolated MV repair for complex disease (anterior or bileaflet prolapse), based on preoperative echocardiographic images. Logistic regression analysis was used to generate propensity scores for risk-adjusted comparisons ( $n=2065$ matched pairs). Durability was assessed by longitudinal recurrence of mitral regurgitation and reoperation.

Results: Compared with patients with simple disease, those undergoing repair of complex pathology were more likely to be younger and female (both $P$ values $<.0001)$ but with similar symptoms $(P=.3)$. The most common repair technique was ring/band annuloplasty (3055/99\% simple vs 3000/98\% complex; $P=.5$ ), followed by leaflet resection (2802/90\% simple vs $2249 / 74 \%$ complex; $P<.0001)$. Among propensity-matched patients, recurrence of severe mitral regurgitation 10 years after repair was $6.2 \%$ for simple pathology versus $11 \%$ for complex pathology $(P=.007)$, reoperation at 18 years was $6.3 \%$ for simple pathology versus $11 \%$ for complex pathology, and 20 -year survival was $62 \%$ for simple pathology versus $61 \%$ for complex pathology $(P=.6)$.

Conclusions: Early surgical intervention has become more common in patients with degenerative MV disease, regardless of valve prolapse complexity or symptom status. Valve repair was associated with similarly low operative risk and timerelated survival but less durability in complex disease. Lifelong annual echocardiographic surveillance after MV repair is recommended, particularly in patients with complex disease. (J Thorac Cardiovasc Surg 2018;156:122-9)

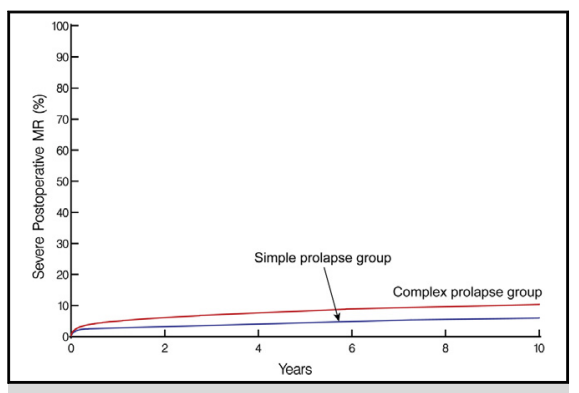

Temporal trend of severe postoperative mitral regurgitation (MR) after mitral valve repair

\section{Central Message}

Degenerative mitral valve repair operations have become increasingly durable. However, lifelong annual echocardiographic surveillance is recommended, particularly for patients with complex disease.

\section{Perspective}

Mitral valve repair for degenerative disease is associated with excellent survival and low operative risk, regardless of valve prolapse complexity. However, repair of complex disease is still less durable and requires lifelong postoperative annual echocardiographic surveillance.

See Editorial Commentary page 130.
From the Departments of ${ }^{\mathrm{a}}$ Thoracic and Cardiovascular Surgery, and ${ }^{\mathrm{c} C a r d i o v a s c u l a r}$ Medicine, Heart and Vascular Institute, and ${ }^{\mathrm{b}}$ Department of Quantitative Health Sciences, Research Institute, Cleveland Clinic, Cleveland, Ohio.

Supported in part by the Gus P. Karos Registry Fund; the David Whitmire Hearst Jr. Foundation; the Marty and Michelle Weinberg and Family Fund; Friends of Cleveland Clinic Foundation; the Delos M. Cosgrove, MD, Chair for Heart Disease Research; the Mary Elizabeth Holdworth Fund; the Judith Dion Pyle Endowed Chair in Heart Valve Research; and the Drs Sidney and Becca Fleischer Heart and Vascular Education Chair.

Read at the 97th Annual Meeting of The American Association for Thoracic Surgery, Boston, Massachusetts, April 29-May 3, 2017.

Received for publication May 1, 2017; revisions received Jan 28, 2018; accepted for publication Feb 23, 2018; available ahead of print April 27, 2018.

Address for reprints: A. Marc Gillinov, MD, Department of Thoracic and Cardiovascular Surgery, Cleveland Clinic, 9500 Euclid Ave, Desk J4-1, Cleveland, OH 44195 (E-mail: gillinom@ccf.org).

$0022-5223 / \$ 36.00$

Copyright (c) 2018 by The American Association for Thoracic Surgery

https://doi.org/10.1016/j.jtcvs.2018.02.102
Degenerative mitral valve disease is the most common indication for mitral valve surgery and is recognized as an important preventable cause of chronic heart failure. ${ }^{1-3}$ The recent American Heart Association/American College of Cardiology guidelines recommend (class IIA) surgical mitral valve repair for asymptomatic patients with chronic severe primary mitral regurgitation (MR) with preserved

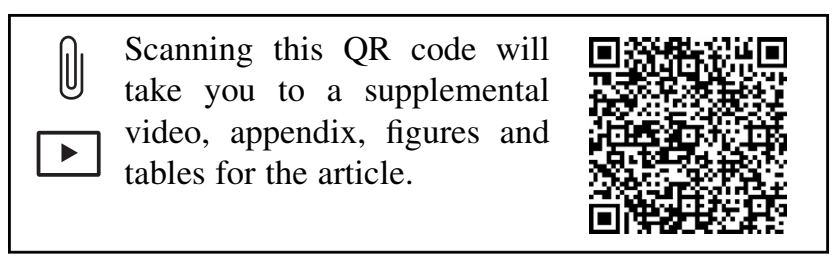




\section{Abbreviations and Acronyms \\ MR = mitral regurgitation \\ NYHA $=$ New York Heart Association}

left ventricular function (ejection fraction $>60 \%$ and end-systolic dimension $<40 \mathrm{~mm}$ ) in whom the likelihood of a successful and durable repair without residual MR is more than $95 \%$, and expected mortality of $<1 \%$ when performed at an experienced heart valve center. ${ }^{4}$

Although there is consensus that repair of posterior leaflet prolapse by resection and annuloplasty is reproducible and durable, outcomes after repair of anterior leaflet and bileaflet prolapse are less certain. ${ }^{5}$ Thus, many cardiologists have been reluctant to recommend surgical intervention in asymptomatic patients with anterior or bileaflet prolapse because of perceived inferior surgical outcomes (Video 1). ${ }^{1,6}$ At a center where surgeons favor mitral valve repair for all subsets of leaflet prolapse, we sought to identify temporal trends in characteristics of patients with simple (posterior leaflet prolapse) and complex (anterior or bileaflet prolapse) degenerative MR undergoing mitral valve repair, determine whether postoperative complications differed after repair of simple versus complex disease, assess recurrent MR over time and prevalence of reoperation after repair in each group, compare long-term survival, and identify factors associated with mortality and durability after repair.

\section{PATIENTS AND METHODS \\ Patients}

From January 1, 1985, to January 1, 2016, 6153 patients underwent primary mitral valve repair for degenerative mitral valve disease with leaflet prolapse (Carpentier type $\left.\mathrm{II}^{7}\right)$ at Cleveland Clinic. Patients with concomitant tricuspid valve repair $(\mathrm{n}=350[5.7 \%])$, closure of an atrial septal defect or patent foramen ovale $(n=274[4.5 \%])$, or surgical ablation for atrial fibrillation ( $\mathrm{n}=750[12 \%])$ are included, but those with severe mitral annular calcification or undergoing other concomitant cardiac operations are not. These 6153 patients represent $96 \%$ of the 6408 patients undergoing primary mitral valve surgery for degenerative disease. The proportion of patients undergoing mitral valve repair has increased steadily, to nearly $100 \%$ in recent years (Figure E1).

Cardiologists usually recommend surgical intervention based on complexity of the valve pathology seen in echocardiographic images. Therefore, simple versus complex degenerative mitral valve disease was classified by review of echocardiographic images. Of 6153 patients, 3101 underwent mitral valve repair for simple disease on preoperative echocardiographic imaging, which represents $97 \%$ of 3183 patients undergoing mitral valve surgery for simple disease (Figure E2, A), and 3052 underwent mitral valve repair for complex disease, which represents $95 \%$ of 3225 patients undergoing mitral valve surgery for complex disease (Figure E2, $B$ ).

\section{Surgical Details}

Full sternotomy was performed in 2351 patients (39\%), partial sternotomy in $1958(32 \%)$, and right minithoracotomy in $693(11 \%)$, and a

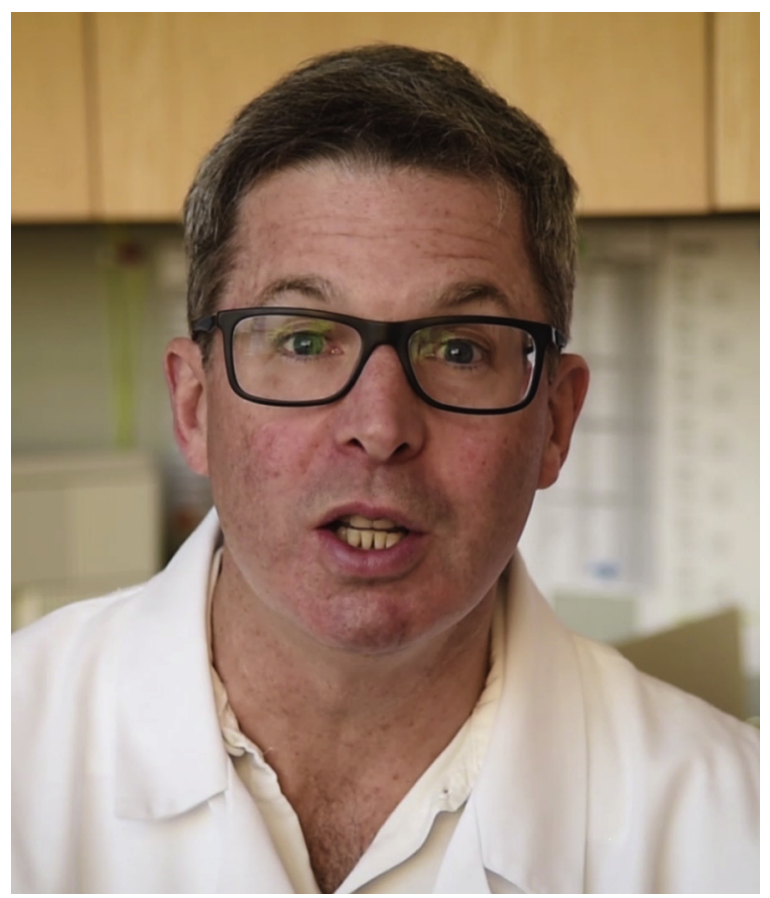

VIDEO 1. Simple versus complex degenerative mitral valve disease. Video available at: https://www.jtcvs.org/article/S0022-5223(18)30896-1/ fulltext.

robotic approach was used in $1045(17 \%)$. Details of surgical approaches for patients undergoing less invasive and robotic mitral valve repair have been described previously. ${ }^{8-10}$

The most common repair techniques included band/ring annuloplasty in $6055(98 \%)$, leaflet resection in $5052(82 \%)$, sliding repair in 2576 $(42 \%)$, insertion of polytetrafluoroethylene chords in $579(9.4 \%)$, chordal transfer in $529(8.6 \%)$, and commissuroplasty in $254(4.1 \%)$. The most common reasons for not using annuloplasty repair were high probability of postrepair systolic anterior motion and valve stenosis due to small size of the annulus. Further details are provided in Appendix E1.

\section{End points}

End points included in-hospital mortality and morbidity, longitudinal persistence or recurrence of MR, reoperation after mitral valve repair, and time-related mortality. In-hospital mortality and complications were defined according to the Society of Thoracic Surgeons National Cardiac Database (see http://www.sts.org/sites/default/files/documents/ STSAdultCVDataSpecificationsV2_81.pdf).

A total of 7719 postoperative echocardiograms were available for 3767 patients $(91 \%)$ in the matched repair group (see Data Analysis and Presentation for matching strategy). However, only a subset of 1085 matched patients have been routinely followed at Cleveland Clinic, with a total of 3370 echocardiograms available. Compared with patients not having follow-up echocardiography, these patients were more likely to be younger and less symptomatic, with a higher prevalence of chordal elongation and use artificial chordae, annuloplasty, and sliding repair techniques (Tables E1 and E2). Details of echocardiographic follow-up are shown in Figures E3 and E4.

For time-related events, patients were followed systematically at 2, 5, 10,15 , and 20 years after surgery by mailed institutional review board-approved questionnaires, telephone interviews, or examination at Cleveland Clinic. Median time for this active follow-up was 6 years, with $25 \%$ of survivors followed for more than 10 years and nearly $5 \%$ for 20 years (Figure E5). 


\section{Data Analysis and Presentation}

The analytic strategy included identifying patient characteristics associated with complex disease, generating a cohort of matched patients using propensity scores, and comparing persistent or recurrent MR longitudinally after repair, survival, and reoperation between matched cohorts. ${ }^{11}$ Data used in these analyses were approved for research by the Cleveland Clinic Institutional Review Board, with patient consent waived. All analyses were performed using SAS statistical software version 9.4 (SAS Institute, Cary, NC) and R version 3.3.1 (R Foundation for Statistical Computing, Vienna, Austria). ${ }^{12}$

\section{Single Versus Complex Prolapse}

Briefly, multivariable logistic regression analysis (PROC LOGISTIC) was used to identify baseline factors from among those listed in Appendix E2 that were associated with complex mitral valve prolapse. To meet assumptions of linearity of ordinal and continuous variables with respect to the logit, we incorporated potentially linearizing transformations of scale in our variable selection strategy. Variable selection, with a $P$ value criterion for retention of variables in the model of .05 , used bagging (bootstrap aggregation) ${ }^{12,13}$ with automated forward stepwise analysis of 1000 resampled data sets. Variables appearing in at least $50 \%$ of analyses were considered reliably statistically significant. This parsimonious model (Table E3) was amplified to form a semisaturated propensity model by adding factors from each class of variables not already represented (see Appendix E2). ${ }^{14,15}$ The final model was solved to generate a propensity score for each patient, then used to identify 2065 propensity-matched pairs $(68 \%$ of possible matched pairs) (Tables E4 and E5, Figure E6, $A$ and $B$ ) with a greedymatching strategy. ${ }^{16}$

In the simple group, patients in the matched cohort were more likely than unmatched patients to be younger and female, had similar preoperative symptoms and cardiac morphology, higher prevalence of preoperative atrial fibrillation and chordal elongation, and similar MV repair techniques (Table E6). In the complex group, patients in the matched cohort were more likely than unmatched patients to be older and male, with similar preoperative symptoms and cardiac morphology, lower prevalence of preoperative atrial fibrillation and chordal elongation, but similar MV repair techniques (Table E7).

\section{Longitudinal Analysis of Persistent or Recurrent MR}

We analyzed the longitudinal pattern of MR grades on surveillance transthoracic echocardiograms using a nonlinear cumulative logistic mixed model. ${ }^{17}$ Prevalence of each MR grade over time was estimated by averaging patient-specific profiles from this model.

\section{Time-Related Events}

Nonparametric estimates of survival and reoperation were assessed by the Kaplan-Meier method and parametric estimates by a multiphase hazard model. ${ }^{18}$ The parametric model was used to resolve a number of phases of instantaneous risk of death/reoperation (hazard function) and to estimate shaping parameters.

\section{Risk Factor Identification}

Risk factors for death, reoperation, and persistent or recurrent MR were identified using the bagging method, with variable selection from those presented in Appendix E2. Procedure characteristics were also included as potential risk factors.

\section{Managing Missing Values}

To account for missing values for some variables in multivariate modeling, we performed 5-fold multiple imputation using a Markov chain Monte Carlo technique. ${ }^{19}$

\section{Presentation}

Categorical variables are summarized as frequency and percentage and were compared using the $\chi^{2}$ test or Fisher exact test when fewer than 5 events were observed in either group. Continuous variables are summarized as mean \pm standard deviation or equivalently as 15 th, 50 th (median), and 85th percentiles when their distribution was skewed, but all were compared using the Wilcoxon rank-sum test to account conservatively for nonnormality of distributions. Mortality and reoperation estimates are accompanied by an asymmetric $68 \%$ confidence interval, comparable to \pm 1 standard error. Trends are displayed using a smoothing spline ( $\mathrm{R}$ statistical software). ${ }^{20}$

\section{RESULTS}

\section{Complex Versus Simple Degenerative Mitral Valve Disease}

Primary isolated mitral valve repair was performed in 3101 patients with simple disease and 3052 patients with complex disease observed by preoperative echocardiography. The percentage of patients diagnosed echocardiographically with complex disease declined in the first decade of our experience (Figure E7). Compared with patients with simple disease, those who underwent repair for complex pathology were more likely to be younger (mean age, $56 \pm 13$ years vs $58 \pm 11$ years) and female (38\% vs $24 \%$ ), with a higher prevalence of leaflet calcification $(2.2 \%$ vs $1.4 \%)$, severe tricuspid valve regurgitation $(5.1 \%$ vs $3.4 \%)$, and preoperative atrial fibrillation $(15 \%$ vs $12 \%$ ) (Table 1$)$.

Compared with patients with simple disease, those who underwent mitral valve repair for complex disease had similar left ventricular end-systolic volume index $(25 \pm 12 \mathrm{~mL} / \mathrm{m}$ vs $24 \pm 11 \mathrm{~mL} / \mathrm{m} ; P=.4)$ and left ventricular mass index $(128 \pm 35 \mathrm{~g} / \mathrm{m}$ vs $128 \pm 36 \mathrm{~g} / \mathrm{m}$; $P=.8$ ).

The most common type of mitral valve repair was ring/ band annuloplasty ( $99 \%$ in the simple group vs $98 \%$ in the complex group), followed by leaflet resection $(90 \%$ in the simple group vs $74 \%$ in the complex group) (Table 2).

\section{Temporal Trends of Preoperative Characteristics}

Cardiac morphology. Preoperative echocardiographic features of patients with degenerative mitral valve disease have changed over time. Left ventricular size and mass decreased steadily over the first decade of our experience in the entire cohort (Figure 1, $A$ and $B)(P<.004)$ as well as in the simple and complex groups (Figure E8, $A$ and $B$, and Figure E9, $A$ and $B$ ).

Clinical presentation. The proportion of patients in New York Heart Association (NYHA) functional class III or IV on presentation declined over the study period, from about $30 \%$ in 1885 to $10 \%$ in 2016 (Figure $2, A)(P<.0001)$. The temporal trend in NYHA functional class for patients with simple disease was similar to that for patients with complex disease (Figure 2, $B$ and $C$ ). 
TABLE 1. Patient characteristics

\begin{tabular}{|c|c|c|c|c|c|}
\hline \multirow[b]{2}{*}{ Characteristic } & \multicolumn{2}{|r|}{ Simple disease $(n=3101)$} & \multicolumn{2}{|r|}{ Complex disease $(n=3052)$} & \multirow[b]{2}{*}{$P$ value } \\
\hline & $\mathbf{n}^{*}$ & n $(\%)$ or mean \pm standard deviation & $\mathbf{n}^{*}$ & n $(\%)$ or mean \pm standard deviation & \\
\hline \multicolumn{6}{|l|}{ Demographic characteristic } \\
\hline Age $(y)$ & 3101 & $58 \pm 11$ & 3052 & $56 \pm 13$ & $<.0001$ \\
\hline Female & 3101 & $744(24)$ & 3052 & $1160(38)$ & $<.0001$ \\
\hline \multicolumn{6}{|l|}{ Cardiac comorbidity } \\
\hline LV ejection fraction $(\%)$ & 2810 & $59 \pm 6.5$ & 2651 & $58 \pm 6.6$ & $<.0001$ \\
\hline LVESVI (mL/m) & 2282 & $24 \pm 11$ & 2162 & $25 \pm 12$ & .4 \\
\hline LV mass index $(\mathrm{g} / \mathrm{m})$ & 2297 & $128 \pm 36$ & 2157 & $128 \pm 35$ & .8 \\
\hline Heart failure & 3100 & $499(16)$ & 3052 & $415(14)$ & .006 \\
\hline Atrial fibrillation & 2902 & $342(12)$ & 2842 & $436(15)$ & $<.0001$ \\
\hline NYHA functional class & 3080 & & 3041 & & .3 \\
\hline I & & $1161(38)$ & & $1121(37)$ & \\
\hline II & & $1566(51)$ & & $1544(51)$ & \\
\hline III & & $310(10)$ & & $343(11)$ & \\
\hline IV & & $43(1.4)$ & & $33(1.1)$ & \\
\hline \multicolumn{6}{|l|}{ Noncardiac comorbidity } \\
\hline Hypertension & 3003 & $1405(47)$ & 2884 & $1068(37)$ & $<.0001$ \\
\hline COPD & 3002 & $175(5.8)$ & 2884 & $176(6.1)$ & .7 \\
\hline \multicolumn{6}{|l|}{ Diabetes } \\
\hline Insulin-treated & 3055 & $13(0.43)$ & 2997 & $9(0.30)$ & .4 \\
\hline Noninsulin-treated & 3055 & $89(2.9)$ & 2997 & $50(1.7)$ & .001 \\
\hline Creatinine (mg/dL) & 2971 & $1.02 \pm 0.46$ & 2842 & $0.98 \pm 0.57$ & $<.0001$ \\
\hline
\end{tabular}

LV, Left ventricle; $L V E S V I$, left ventricular end-systolic volume index; NYHA, New York Heart Association; COPD, chronic obstructive pulmonary disease. *Patients with data available.

In-hospital outcomes. Among propensity-matched patients, the simple and complex groups experienced similar in-hospital mortality $(0.048 \%$ vs $0.097 \%)$, occurrence of stroke $(0.87 \%$ vs $1.4 \%)$, new-onset atrial fibrillation ( $28 \%$ vs $29 \%)$, respiratory failure $(1.4 \%$ vs $2.4 \%)$, septicemia $(0.20 \%$ vs $0.25 \%)$, reexploration for bleeding

TABLE 2. Mitral valve pathophysiology and repair techniques

\begin{tabular}{|c|c|c|c|c|c|}
\hline \multirow[b]{2}{*}{ Characteristic } & \multicolumn{2}{|c|}{ Simple disease $(n=3101)$} & \multicolumn{2}{|c|}{ Complex disease $(n=3052)$} & \multirow[b]{2}{*}{$P$ value } \\
\hline & $\mathbf{n}^{*}$ & n (\%) & $\mathbf{N}^{*}$ & n (\%) & \\
\hline \multicolumn{6}{|l|}{ Pathophysiology } \\
\hline Regurgitation grade & 2979 & & 2849 & & $<.0001$ \\
\hline Moderate & & $37(1.2)$ & & $89(3.1)$ & \\
\hline Moderate to severe & & $393(13)$ & & $709(25)$ & \\
\hline Severe & & $2549(86)$ & & $2051(72)$ & \\
\hline Leaflet cleft & 2884 & $93(3.2)$ & 2876 & $111(3.9)$ & .19 \\
\hline Chordal rupture & 2884 & $2225(77)$ & 2876 & $1521(53)$ & $<.0001$ \\
\hline Chordal elongation & 2884 & $614(21)$ & 2876 & $849(30)$ & $<.0001$ \\
\hline Leaflet calcification & 2884 & $40(1.4)$ & 2876 & $63(2.2)$ & .02 \\
\hline \multicolumn{6}{|l|}{ Repair technique } \\
\hline Annuloplasty & 3101 & 3055 (99) & 3052 & $3000(98)$ & .5 \\
\hline Leaflet resection & 3101 & $2803(90)$ & 3052 & $2249(74)$ & $<.0001$ \\
\hline Sliding repair & 3101 & $1199(39)$ & 3052 & $1377(45)$ & $<.0001$ \\
\hline Artificial chordae & 3101 & $180(5.8)$ & 3052 & 399 (13) & $<.0001$ \\
\hline Chordal transfer & 3101 & $59(1.9)$ & 3052 & $470(15)$ & $<.0001$ \\
\hline Commissuroplasty & 3101 & $76(2.5)$ & 3052 & $178(5.8)$ & $<.0001$ \\
\hline \multicolumn{6}{|l|}{ Incision characteristic } \\
\hline Full sternotomy & 3041 & $1075(35)$ & 3006 & $1276(42)$ & $<.0001$ \\
\hline Thoracotomy & 3041 & 377 (12) & 3006 & $316(11)$ & $<.0001$ \\
\hline Partial sternotomy & 3041 & $986(32)$ & 3006 & $972(32)$ & $<.0001$ \\
\hline Robotic & 3041 & $603(20)$ & 3006 & $442(15)$ & $<.0001$ \\
\hline
\end{tabular}

*Patients with data available. 

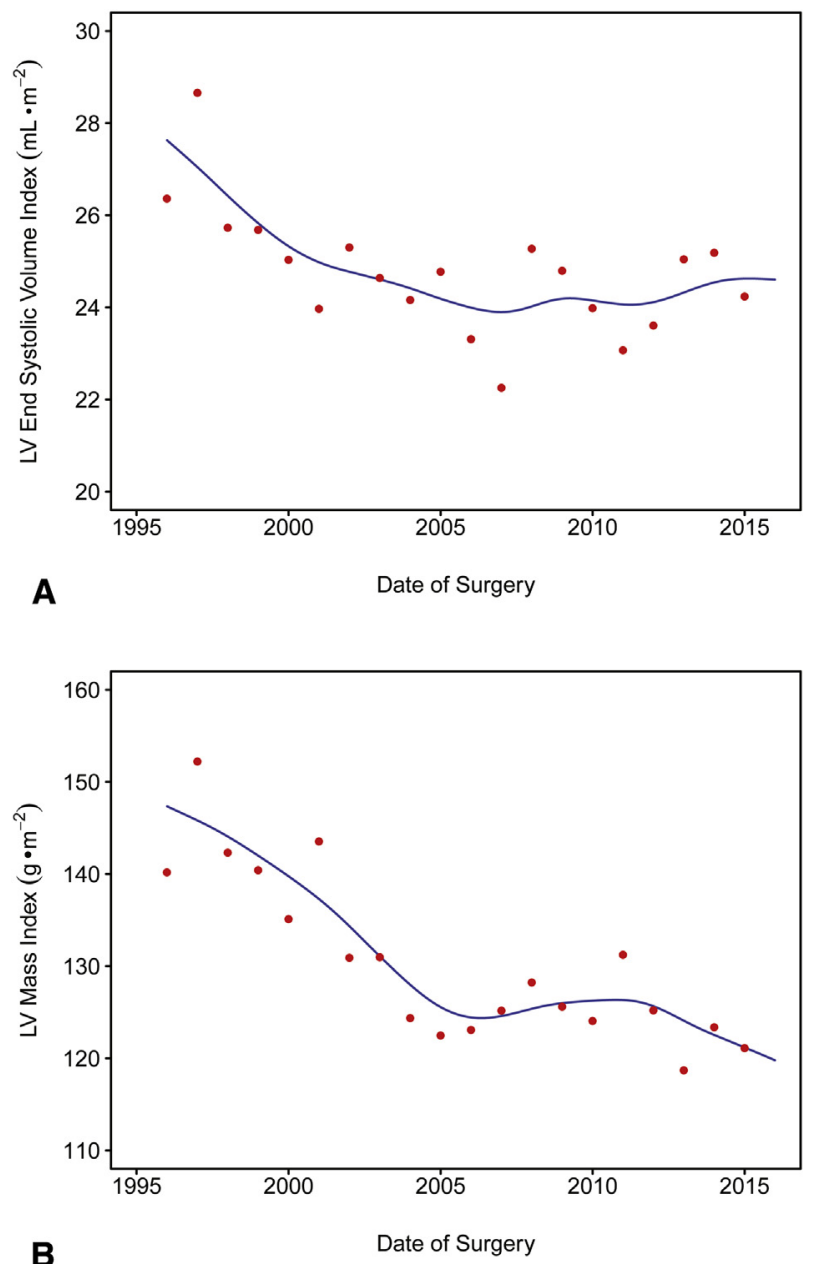

FIGURE 1. Temporal trends among patients undergoing mitral valve repair. A, Left ventricular $(L V)$ end-systolic volume index. Solid line is a smoothing spline curve and filled circles represent the mean baseline LV end-systolic volume index each year. B, LV mass index.

$(2.2 \%$ vs $2.7 \%)$, renal failure $(0.058 \%$ vs $0.17 \%)$, and length of intensive care unit stay (15th, 50th, and 85th percentiles, 22, 24, and 28 hours vs 21,24 , and 28 hours, respectively, for both groups) after repair $(P \geq .05$ for all $)$ (Table 3).

Recurrent MR. Prevalence of persistent or recurrent MR demonstrated an early increase within the first month after repair followed by a slow progression in the months and years thereafter (Figure E10, $A$ and $B$ ). Among propensity-matched patients, $95 \%$ of those in the simple group and $93 \%$ of those in the complex group had no or mild MR within 1 month after valve repair. By 10 years, an estimated $86 \%$ in the simple group had no or mild MR, $7.9 \%$ had moderate MR, and $6.2 \%$ had severe MR, versus $77 \%$ with no or mild MR, $12 \%$ with moderate MR, and $11 \%$ with severe MR in the complex group $(P=.01$ in the early phase and $P=.007$ in the late phase after repair) (Figure 3 ).
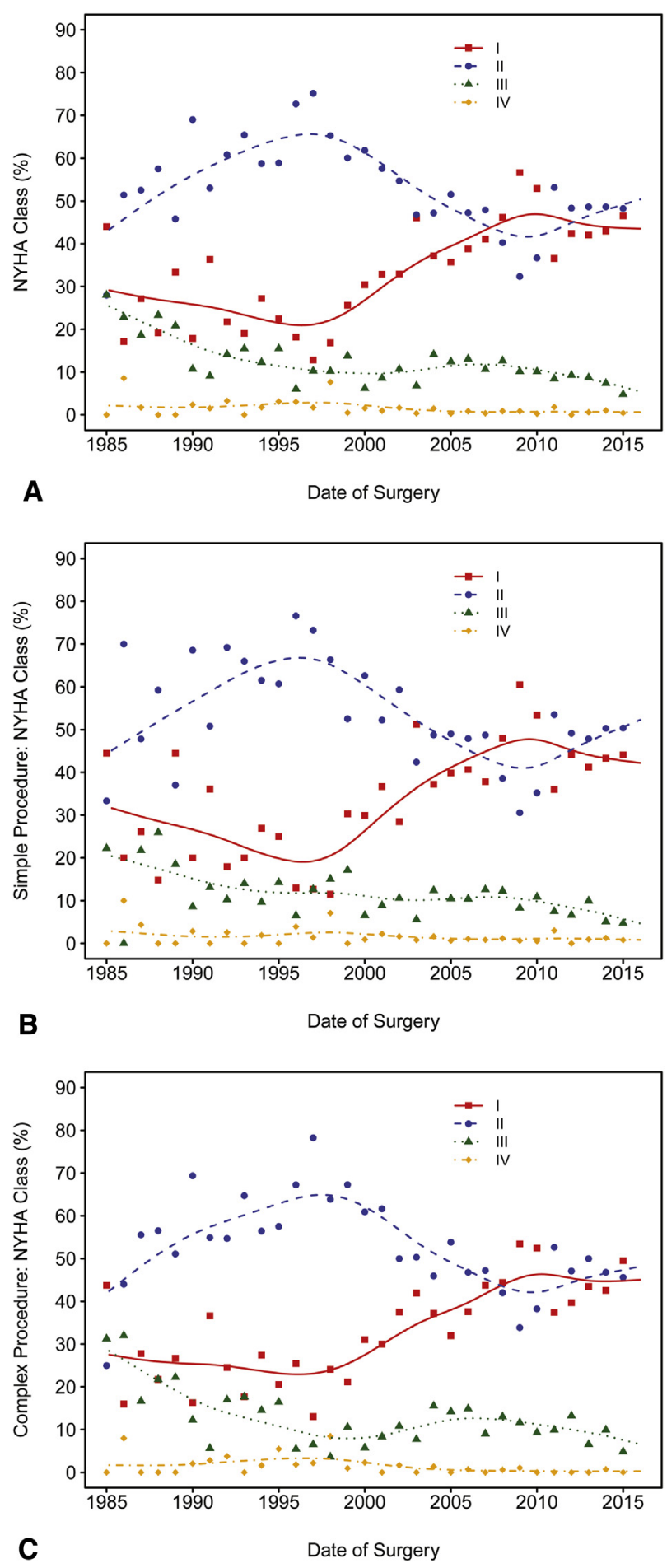

FIGURE 2. Temporal trend in New York Heart Association (NYHA) functional class among patients presenting for mitral valve repair. Solid line is a smoothing spline curve and symbols represent the mean percentage of patients with NYHA data available each year. A, All patients. B, Patients with simple disease. C, Patients with complex disease.

Incremental risk factors for early persistence or progression of MR in the entire cohort were higher preoperative right ventricular systolic pressure and left atrial volume 
TABLE 3. Postoperative in-hospital complications among propensity-matched patients

\begin{tabular}{|c|c|c|c|c|c|}
\hline \multirow[b]{2}{*}{ Complication } & \multicolumn{2}{|c|}{ Simple disease $(n=2065)$} & \multicolumn{2}{|c|}{ Complex disease $(n=2065)$} & \multirow[b]{2}{*}{$P$ value } \\
\hline & $\mathbf{n}^{*}$ & n (\%) & n* & n (\%) & \\
\hline Death & 2065 & $1(0.048)$ & 2065 & $2(0.097)$ & .4 \\
\hline Stroke & 2065 & $18(0.87)$ & 2065 & $28(1.4)$ & .14 \\
\hline Atrial fibrillation & 1724 & $491(28)$ & 1717 & $491(29)$ & .9 \\
\hline Respiratory complication & 1383 & $19(1.4)$ & 1443 & $34(2.4)$ & .05 \\
\hline Septicemia & 1989 & $4(0.20)$ & 1970 & $5(0.25)$ & .7 \\
\hline Reoperation for bleeding & 2065 & $45(2.2)$ & 2065 & $56(2.7)$ & .3 \\
\hline Renal failure & 1729 & $1(0.058)$ & 1749 & $3(0.17)$ & .6 \\
\hline
\end{tabular}

*Patients with data available.

index, earlier date of operation, placement of artificial chordae, complex disease, and not having leaflet resection in the late phase (Table E8 and Figure E11, $A$ and $B$ ).

Reoperation. Among propensity-matched patients, 97 underwent reoperation after mitral valve repair. Indications were recurrence of severe MR in 80 patients $(82 \%)$ ) (tear in leaflet in 14 patients [14\%], failure of artificial chord in 6 patients [6\%], failure of annuloplasty in 2 patients [2\%], progression of degenerative disease in 15 patients $[15 \%]$, unknown reason in 43 patients [ $44 \%$ ], symptomatic systolic anterior motion in 9 patients [9\%], severe MV stenosis in 4 patients [4\%], and endocarditis in 4 patients [4\%]). Risk of reoperation at 18 years after repair was $6.3 \%$ for those with simple disease versus $11 \%$ for those with complex disease $(P=.03$ in the early hazard phase and $P=.13$ in the late rising hazard phase) (Figure E12).

Incremental risk factors for reoperation in the entire cohort were earlier date of operation, higher preoperative NYHA functional class, and higher preoperative left atrial

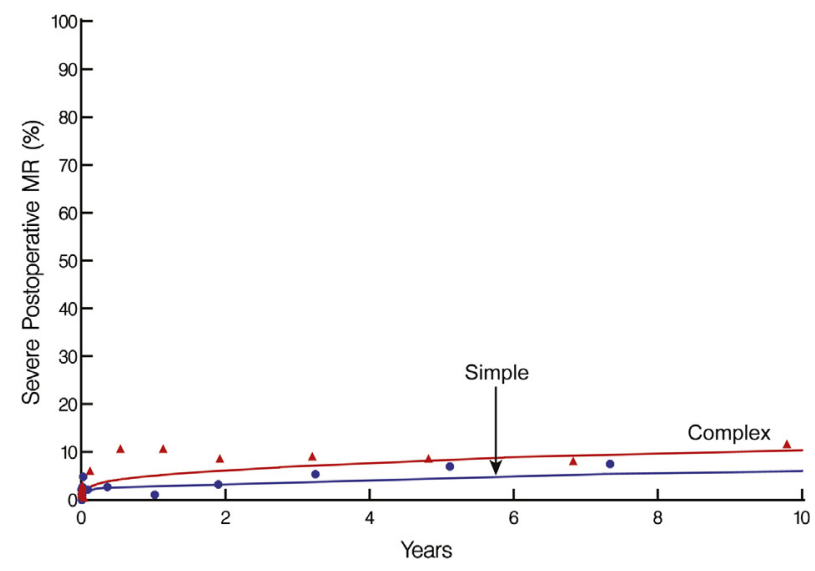

FIGURE 3. Temporal trend of severe postoperative mitral regurgitation $(M R)$ after mitral valve repair in propensity-matched patients. Solid lines represent ensemble average of percentage of patients with severe postoperative MR. Symbols represent data grouped (without regard to repeated measurements) within time frames to provide a crude verification of model fit. Blue line indicates matched simple prolapse group and red line indicates matched complex prolapse group. volume index in the early phase, and mitral valve repair without annuloplasty and without leaflet resection in the late phase. Complex disease was a risk factor for reoperation both early and late after repair (Table E9 and Figure E13, $A$ and $B$ ).

Survival. Among propensity-matched patients, survival at 20 years after repair was $62 \%$ for those with simple disease versus $61 \%$ for those with complex valve disease $(P=.6$ in both the constant and late phases) (Figure 4).

Incremental risk factors for death in the entire cohort were older age, lower preoperative left ventricular ejection fraction, heart failure, prior stroke, and earlier date of operation in the constant phase, and higher preoperative body mass index, prior myocardial infarction, carotid disease, and higher preoperative tricuspid and pulmonary valve regurgitation in the late hazard phase. Complexity of the valve was not associated with death in either phase (Table E10).

\section{DISCUSSION \\ Key Findings}

In recent years, early surgical intervention-before development of symptoms, atrial fibrillation, or changes in left ventricular structure and function-has become more common in patients with degenerative mitral valve disease, regardless of complexity of the degenerative lesion. Valve repair was associated with similarly low operative risk and better time-related survival, but greater progression of MR and late reoperations in complex versus simple disease. Earlier date of operation and placing artificial chordae in complex disease, and not having leaflet resection and annuloplasty were associated with lower durability of MV repair.

\section{Current Clinical Practice}

Although there is no debate among experts concerning mitral valve repair for severe symptomatic degenerative MR (class IB recommendation) ${ }^{4}$ discordance persists in mainstream clinical practice regarding early correction of severe asymptomatic degenerative MR. Approximately 


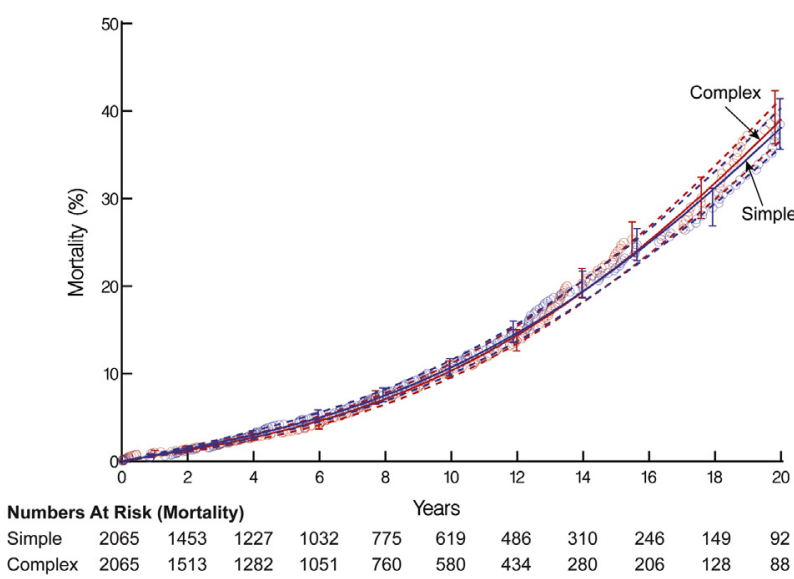

FIGURE 4. Mortality after mitral valve repair in propensity-matched patients. Each symbol represents a death positioned on the vertical axis by the Kaplan-Meier estimator; vertical bars are $68 \%$ confidence limits equivalent to \pm 1 standard error. Solid lines are parametric hazard estimates enclosed within a dashed $68 \%$ confidence band. Blue lines and circles indicate simple prolapse group and red lines and circles indicate complex prolapse group.

$30 \%$ to $60 \%$ of such patients in the United States and $30 \%$ in Europe undergo surgery. Although American Heart Association/American College of Cardiology guidelines ${ }^{4}$ provide a class IIA recommendation for early operation in asymptomatic patients, European guidelines ${ }^{21}$ do not provide a strong endorsement of this course. However, surgical referral after development of left ventricle enlargement and dysfunction results in excess early and late mortality as well as increased risk of heart failure, as we also observed in our study. ${ }^{1,4}$

In clinical practice, the site of prolapse (ie, anterior, posterior, or bileaflet) has a potential influence on the likelihood of surgical referral in patients with severe asymptomatic MR. Although cardiologists agree that early surgical referral of patients with simple degenerative mitral valve disease (posterior prolapse) is supported by evidence, many have been reluctant to recommend surgical intervention for asymptomatic patients with complex disease (ie, anterior or bileaflet prolapse), fearing that surgical outcomes are inferior to watchful waiting. Patients with complex disease previously presented with more symptoms and greater changes in cardiac structure and function than did patients with simple disease and experienced slightly inferior outcomes. ${ }^{5,22,23}$ Recently, patients have been referred for early correction of severe MR regardless of the type and extent of valve prolapse, as shown in this study. We demonstrate that this practice does not compromise outcomes.

\section{Durability of Repair}

Historically, repair of an anterior leaflet has been more challenging than posterior leaflet repair and has been accompanied by reduced durability. ${ }^{5,23-25}$ Anterior repair techniques have evolved from chordal shortening and chordal transfer to insertion of polytetrafluoroethylene chordae. $^{5,26-28}$ Creation of artificial chordae has been associated with excellent durability and is amenable to less invasive approaches, making it our preferred technique in recent years.

In an earlier series, ${ }^{5}$ we compared 252 isolated anterior repairs with 2650 isolated posterior repairs and found that recurrence of MR was more likely early after anterior repair. In the current study, we extended our experience for 10 more years and found similar results. However, more recent operation was associated with higher durability. Possible explanations for these findings include evolution of anterior leaflet repair techniques and increased surgeon experience.

Patients with bileaflet prolapse were included in the group with complex disease. Many of these patients have Barlow disease. Although such valves appear quite complex, successful repair is often achievable by a posterior leaflet repair alone (Appendix E3). In particular, when the valve exhibits bileaflet prolapse and the MR jet is centrally or anteriorly directed, posterior leaflet resection (with or without a sliding repair) and annuloplasty generally result in a successful repair. In contrast, patients with a posteriorly directed MR jet require an anterior leaflet procedure.

\section{Survival}

Evidence supporting similar survival after repair for simple and complex mitral valve disease has accumulated over the past decades. ${ }^{5,29-31}$ In earlier reports, unadjusted survival of patients presenting with anterior disease was inferior to that of those presenting with posterior disease. This was likely attributable to more pronounced changes in cardiac structure and function at the time of surgical referral. ${ }^{5}$ Our current work demonstrates similar excellent survival among patients with simple and complex disease as long as they are referred before developing left ventricle damage and dysfunction.

\section{Limitations}

This was a nonrandomized clinical study with possible selection bias. However, our approach was to consider degree of prolapse as a natural experiment and to use propensity matching of variables other than the prolapse itself to propensity match patients for assessing outcomes. Nevertheless, this methodology cannot account for unmeasured or undocumented variables. Late postoperative echocardiographic follow-up was limited to patients who routinely returned to our institution for surveillance clinic visits (see Appendix E3). However, sufficient echocardiographic data were available to estimate valve durability to 10 years. Furthermore, because of limitations of joint modeling techniques with longitudinal measures and survival, the analysis 
of MR persistence or progression does not account for death as a competing risk. Death, although uncommon, was another potential limitation if it was informative of recurring MR.

This study extended over more than 2 decades, during which time mitral valve repair techniques changed. As such, date of operation was included in the propensity model. After matching, there was no statistically significant difference between the simple and complex disease groups.

\section{CONCLUSIONS}

Mitral valve repair for degenerative MR is associated with low operative risk and excellent time-related survival but lower repair durability in complex disease. Mitral valve repair for complex disease requires lifelong postoperative annual echocardiographic surveillance.

\section{Conflict of Interest Statement}

Dr Gillinov is a consultant for CryoLife Technologies, Kennesaw, Ga; Edwards Lifesciences, Irvine, Calif; Medtronic, Minneapolis, Minn; St Jude Medical, Minneapolis, Minn; Abbott Laboratories, Chicago, Ill; and AtriCure, Mason, Ohio; and receives research funding from Abbott. Dr Mick is a consultant for Medtronic. All other authors have nothing to disclose with regard to commercial support.

\section{References}

1. Suri RM, Vanoverschelde JL, Grigioni F, Schaff HV, Tribouilloy C, Avierinos JF, et al. Association between early surgical intervention vs watchful waiting and outcomes for mitral regurgitation due to flail mitral valve leaflets. JAMA. 2013;310:609-16.

2. Kang DH, Kim JH, Rim JH, Kim MJ, Yun SC, Song JM, et al. Comparison of early surgery versus conventional treatment in asymptomatic severe mitral regurgitation. Circulation. 2009;119:797-804.

3. Enriquez-Sarano M, Avierinos JF, Messika-Zeitoun D, Detaint D, Capps M, Nkomo V, et al. Quantitative determinants of the outcome of asymptomatic mitral regurgitation. N Engl J Med. 2005;352:875-83.

4. Nishimura RA, Otto CM, Bonow RO, Carabello BA, Erwin JP III, Fleisher LA, et al. 2017 AHA/ACC focused update of the 2014 AHA/ACC guideline for the management of patients with valvular heart disease: a report of the American College of Cardiology/American Heart Association task force on clinical practice guidelines. Circulation. 2017;135:e1159-95.

5. Gillinov AM, Blackstone EH, Alaulaqi A, Sabik JF III, Mihaljevic T, Svensson LG, et al. Outcomes after repair of the anterior mitral leaflet for degenerative disease. Ann Thorac Surg. 2008;86:708-17.

6. Yazdchi F, Koch CG, Mihaljevic T, Hachamovitch R, Lowry AM, He J, et al. Increasing disadvantage of "watchful waiting" for repairing degenerative mitral valve disease. Ann Thorac Surg. 2015;99:1992-2000.

7. Carpentier A. Cardiac valve surgery-the "French correction." J Thorac Cardiovasc Surg. 1983:86:323-37.

8. Schroeyers P, Wellens F, De Geest R, Degrieck I, Van Praet F, Vermeulen Y, et al. Minimally invasive video-assisted mitral valve surgery: our lessons after a 4-year experience. Ann Thorac Surg. 2001;72:S1050-4.

9. Cosgrove DM III, Sabik JF, Navia JL. Minimally invasive valve operations. Ann Thorac Surg. 1998;65:1535-9.
10. Suri RM, Dearani JA, Mihaljevic TM, Chitwood WR, Murphy DA, Trento A et al. Mitral valve repair using robotic technology: safe, effective, and durable J Thorac Cardiovasc Surg. 2016;151:1450-4.

11. Javadkasgari H, Gillinov AM, Idrees JJ, Mihaljevic T, Suri RM, Raza S, et al Valve repair is superior to replacement in most patients with coexisting degenerative mitral valve and coronary artery diseases. Ann Thorac Surg. 2017;103 1833-41.

12. Breiman L. Bagging predictors. Machine Learning. 1996;24:123-40.

13. Blackstone EH. Breaking down barriers: helpful breakthrough statistical methods you need to understand better. J Thorac Cardiovasc Surg. 2001;122: 430-9.

14. Rosenbaum PR, Rubin DB. The central role of the propensity score in observational studies for causal effects. Biometrika. 1983;70:41-55.

15. Sauerbrei W, Schumacher M. A bootstrap resampling procedure for model building: application to the Cox regression model. Stat Med. 1992;11: 2093-109

16. Parsons LS. Reducing bias in a propensity score matched-pair sample using greedy matching techniques. In: Proceedings of the twenty-sixth annual SAS Users Group International Conference; 2001:214-26.

17. Rajeswaran J, Blackstone EH. A multiphase non-linear mixed effects model: an application to spirometry after lung transplantation. Stat Methods Med Res. 2017; 26:21-42.

18. Blackstone EH, Naftel DC, Turner ME Jr. The decomposition of time-varying hazard into phases, each incorporating a separate stream of concomitant information. J Am Stat Assoc. 1986;81:615-24.

19. Rubin DB. Multiple Imputation for Non-response in Surveys. New York: Wiley 1987.

20. Ripley BD, Maechler MR. Implementation: fit a smoothing spline. Available at: http://stat.ethz.ch/R-manual/R-patched/library/stats/html/smooth.spline.html. Accessed April 10, 2018

21. Vahanian A, Alfieri O, Andreotti F, Antunes MJ, Baron-Esquivias G Baumgartner $\mathrm{H}$, et al. Guidelines on the management of valvular heart disease (version 2012). Eur Heart J. 2012;33:2451-96.

22. David TE, Ivanov J, Armstrong S, Christie D, Rakowski H. A comparison of outcomes of mitral valve repair for degenerative disease with posterior, anterior, and bileaflet prolapse. J Thorac Cardiovasc Surg. 2005;130:1242-9.

23. Suri RM, Schaff HV, Dearani JA, Sundt TM III, Daly RC, Mullany CJ, et al. Survival advantage and improved durability of mitral repair for leaflet prolapse subsets in the current era. Ann Thorac Surg. 2006;82:819-26.

24. Adams DH, Anyanwu AC, Rahmanian PB, Filsoufi F. Current concepts in mitral valve repair for degenerative disease. Heart Fail Rev. 2006;11:241-57.

25. Mick S, McCurry K, Navia J, Gillinov M. How long will my repair last, doctor? Additional data on the durability of mitral valve repair. J Thorac Cardiovasc Surg. 2017; 154:831.

26. Gillinov AM, Banbury MK. Pre-measured artificial chordae for mitral valve repair. Ann Thorac Surg. 2007;84:2127-9.

27. De Bonis M, Lorusso R, Lapenna E, Kassem S, De Cicco G, Torracca L, et al Similar long-term results of mitral valve repair for anterior compared with posterior leaflet prolapse. J Thorac Cardiovasc Surg. 2006;131:364-70.

28. Ghavidel AA, Samiei N, Javadikasgari H, Bashirpour K. Premeasured neochordae loop maker: a new technology in mitral valve repair. Innovations (Phila). 2013;8:443-9.

29. Nishimura RA, Otto C. 2014 ACC/AHA valve guidelines: earlier intervention for chronic mitral regurgitation. Heart. 2014;100:905-7.

30. Nishimura RA, Otto CM, Bonow RO, Carabello BA, Erwin JP III Guyton RA, et al. 2014 AHA/ACC guideline for the management of patients with valvular heart disease: a report of the American College of Cardiology/ American Heart Association task force on practice guidelines. Circulation. 2014;129:e521-643.

31. Suri RM, Schaff HV, Enriquez-Sarano M. Mitral valve repair in asymptomatic patients with severe mitral regurgitation: pushing past the tipping point. Semin Thorac Cardiovasc Surg. 2014;26:95-101.

Key Words: mitral valve repair, mitral valve surgery 


\section{APPENDIX E1. ECHOCARDIOGRAPHIC VERSUS SURGICAL FINDINGS}

Both preoperative transthoracic echocardiographic and surgical findings are subject to observation bias. Although echocardiograms may show prolapse above the annulus plane, this visual interpretation depends on image quality and orientation as well as interobserver variability. What a surgeon finds and the repair performed may or may not be consistent with preoperative diagnosis and intraoperative echocardiographic findings under altered loading conditions.

Thus, we focused our analyses on the cardiologic diagnosis that patients arrive with in the operating room. In the simple prolapse group, 2939 of 3101 patients underwent repair solely of the posterior leaflet, and 7, 79, and 76 underwent anterior-only repair, bileaflet repair, and annuloplastyonly repair, respectively. In the complex prolapse group, 652 of 3052 patients underwent bileaflet repair, and 1962, 308 , and 130 underwent posterior-only repair, anterioronly repair, and annuloplasty-only repair.

Preoperative echocardiographic diagnosis versus surgical findings

\begin{tabular}{lccc}
\hline \multirow{2}{*}{$\begin{array}{c}\text { Repair } \\
\text { performed }\end{array}$} & \multicolumn{3}{c}{ Prolapse on preoperative echocardiogram } \\
\cline { 2 - 4 } & $\begin{array}{c}\text { Anterior } \\
\text { only }(\mathbf{n}=\mathbf{4 2 4})\end{array}$ & $\begin{array}{c}\text { Posterior } \\
\text { only }(\mathbf{n}=\mathbf{3 1 0 1})\end{array}$ & $\begin{array}{c}\text { Bileaflet } \\
(\mathbf{n}=\mathbf{2 6 2 8})\end{array}$ \\
\hline Posterior only & $104(25)$ & $2939(95)$ & $1858(71)$ \\
Anterior only & $211(50)$ & $7(0.23)$ & $97(3.7)$ \\
Bileaflet & $74(17)$ & $79(2.5)$ & $578(22)$ \\
\hline Annuloplasty only & $35(8.3)$ & $76(2.5)$ & $95(3.6)$ \\
\hline Values are presented as $\mathrm{n}(\%)$. & &
\end{tabular}

\section{APPENDIX E2. VARIABLES INCLUDED IN THE ANALYSES}

*Variables used in the propensity model; procedure variables were considered as risk factors only for the outcome models (mortality, reoperation, and mitral valve regurgitation).

\section{Patient Variables}

Demographic characteristics: Age (y), ${ }^{*}$ sex, ${ }^{*}$ race (white, ${ }^{*}$ black,* or other), weight $(\mathrm{kg})$, height $(\mathrm{cm})$, weight/height ratio,* body surface area $\left(\mathrm{m}^{2}\right)$, and body mass index.

Symptoms: New York Heart Association functional class (I-IV).*

Pathology aortic valve regurgitation (yes/no, ${ }^{*}$ grade*), mitral valve regurgitation grade, ${ }^{*}$ pulmonary valve regurgitation (yes/no),* and tricuspid valve regurgitation (yes/no,* grade*).

Ventricular dysfunction: Prior myocardial infarction.*

Cardiac comorbidity: Atrial fibrillation,* complete heart block or pacer,* ventricular arrhythmia, ${ }^{*}$ heart failure, ${ }^{*}$ and history of endocarditis.*
Noncardiac comorbidity: Peripheral arterial disease, * carotid disease,* hypertension, ${ }^{*}$ pharmacologically treated diabetes,* chronic obstructive pulmonary disease, ${ }^{*}$ history of smoking, ${ }^{*}$ stroke, ${ }^{*}$ creatinine $(\mathrm{mg} / \mathrm{dL})$, blood urea nitrogen $(\mathrm{mg} / \mathrm{dL}),{ }^{*}$ bilirubin $(\mathrm{mg} / \mathrm{dL}),{ }^{*}$ creatinine clearance $(\mathrm{mL} / \mathrm{min})$, ${ }^{*}$ glomerular filtration rate (modification of diet in renal disease; $\mathrm{mL} / \mathrm{min} / 1.73 \mathrm{~m}^{2}$ ), hematocrit $(\%)$, * total cholesterol $(\mathrm{mg} / \mathrm{dL}){ }^{*}$ high-density lipoprotein cholesterol $(\mathrm{mg} / \mathrm{dL}),{ }^{*}$ low-density lipoprotein cholesterol $(\mathrm{mg} / \mathrm{dL}),{ }^{*}$ and triglycerides $(\mathrm{mg} / \mathrm{dL})$.*

Coronary artery disease: Systems with $>50 \%$ stenosis (left anterior descending coronary artery,* left circumflex coronary artery,* and right coronary artery*), number of systems with $>50 \%$ stenosis.

Mitral valve pathologies: Calcification, ${ }^{*}$ leaflet calcification,* thickening/fibrosis,* chordal thickening/fibrosis,* leaflet thickening/fibrosis, ${ }^{*}$ chordal elongation, ${ }^{*}$ cleft leaflet, $*$ dilated annulus, ${ }^{*}$ chordal rupture, ${ }^{*}$ and left ventricular enlargement.*

Right ventricular function: Systolic pressure (mm Hg).*

\section{Left Ventricle Variables}

Structure: Inner diameter in diastole $(\mathrm{cm}), *$ inner diameter in systole $(\mathrm{cm}),{ }^{*}$ diastolic volume $(\mathrm{mL}),{ }^{*}$ systolic volume $(\mathrm{mL}),{ }^{*}$ diastolic volume index $(\mathrm{mL} / \mathrm{m}),{ }^{*}$ systolic volume index $(\mathrm{mL} / \mathrm{m})$, and calculated left ventricle relative wall thickness.*

Function: Fractional shortening,* left ventricular ejection fraction $(\%)$.*

Hypertrophy: Mass $(\mathrm{g})$, mass index $(\mathrm{g} / \mathrm{m}),{ }^{*}$ posterior wall thickness $(\mathrm{cm}),{ }^{*}$ and septal thickness $(\mathrm{cm}){ }^{*}$

\section{Left Atrial Variables}

Size: Left atrial diameter $(\mathrm{cm})$, calculated unscaled left atrial volume $(\mathrm{mL})$, and unscaled left atrial volume index $(\mathrm{mL} / \mathrm{m}){ }^{*}$

Experience date of operation (years since January 1, 1985).*

\section{Procedure Variables}

Operation: Tricuspid valve surgery, any atrial fibrillation procedure, and congenital atrial septal defect/patent foramen ovale suture closure.

Repair techniques: Annuloplasty, leaflet resection, triangular resection, sliding repair, artificial chordae, chordal transfer, and commissuroplasty. 
APPENDIX E3. LONGITUDINAL

\section{ECHOCARDIOGRAPHIC ASSESSMENT OF} MITRAL VALVE REGURGITATION AFTER REPAIR

Because Cleveland Clinic is a high-volume referral center for mitral valve repair, most of our patients come from outside our region. Therefore, their follow-up surveillance is at their local centers. It has rarely been possible to obtain follow-up echocardiographic images or even reports, so we have estimated residual or recurrent mitral regurgitation based on echocardiograms obtained during follow-up surveillance at Cleveland Clinic. As seen in Figure E4, these echocardiograms were obtained for the most part during routine yearly clinic visits.

Patients followed at our institution were slightly older with a slightly higher ejection fraction, and had more heart failure, renal disease, and diabetes than patients followed elsewhere. They also experienced more chordal disease (Tables E1 and E2).

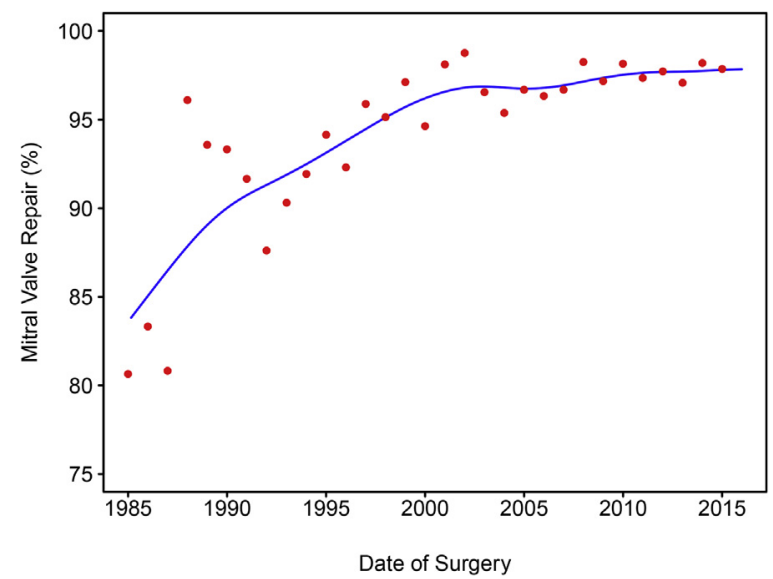

FIGURE E1. Temporal trend of mitral valve repair for all patients with isolated degenerative disease. Solid line is a smoothing spline curve, and filled circles represent percentage of patients with a mitral valve repair each year.
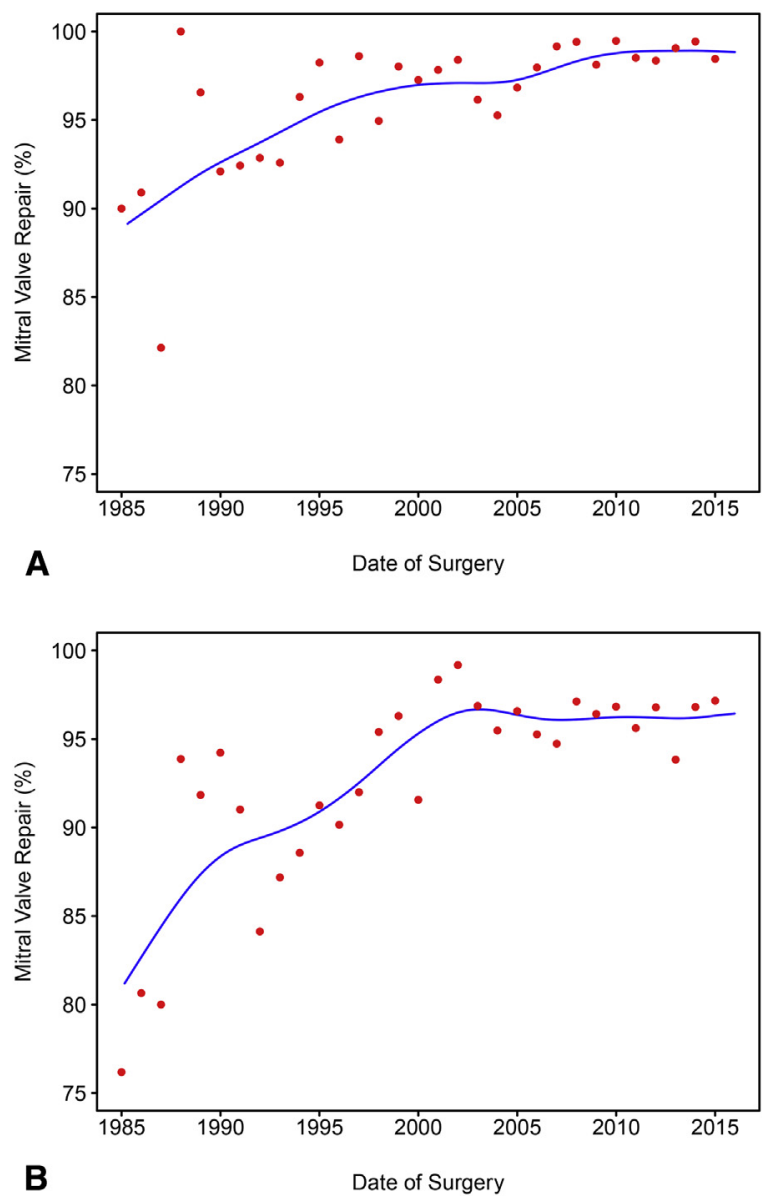

FIGURE E2. Temporal trend of mitral valve repair. Solid line is a smoothing spline curve, and filled circles represent mean percentage of patients with a mitral valve repair each year. A, Patients with simple disease. B, Patients with complex disease. 
Propensity-matched Simple Patients

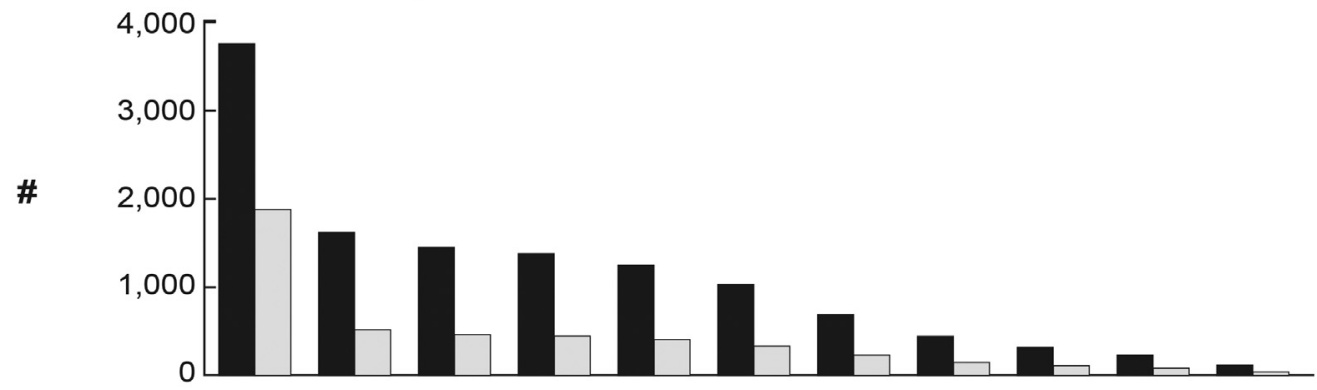

Propensity-matched Complex Patients

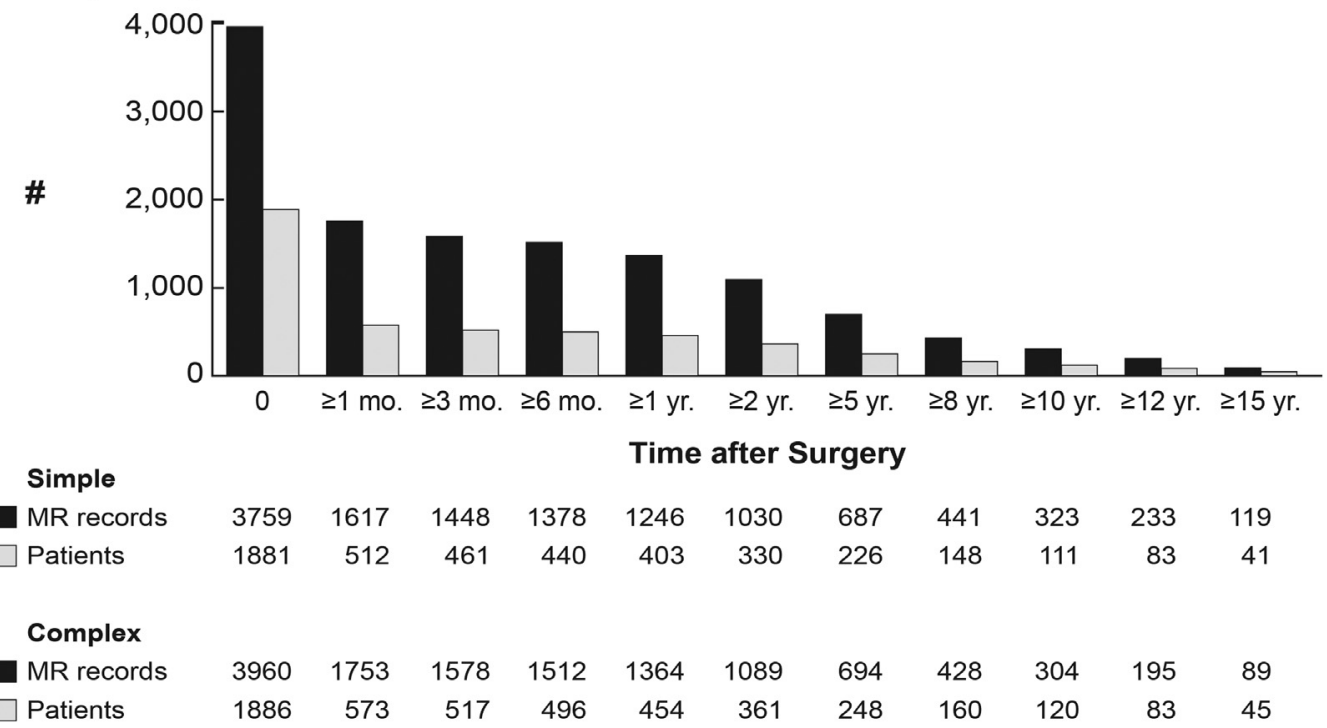

FIGURE E3. Number of propensity-matched patients with mitral regurgitation $(M R)$ records available at and beyond various time points, and number of MR records available for analysis. 

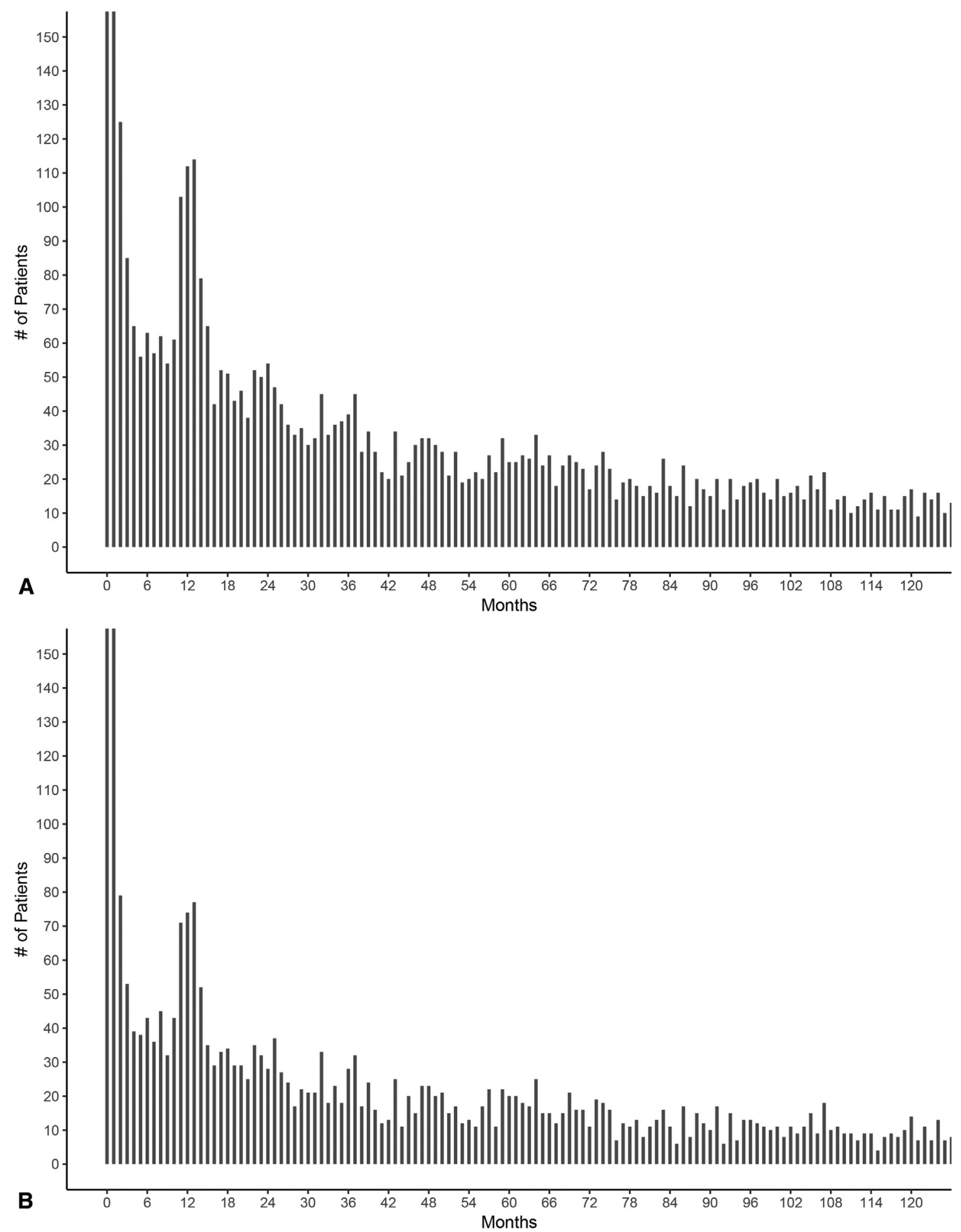

FIGURE E4. Number of patients with postoperative echocardiograms at monthly intervals. Note yearly increases in frequency of echocardiographic measurements, typical of regularly scheduled follow-up examinations. A, Entire cohort. B, Propensity-matched cohort. 


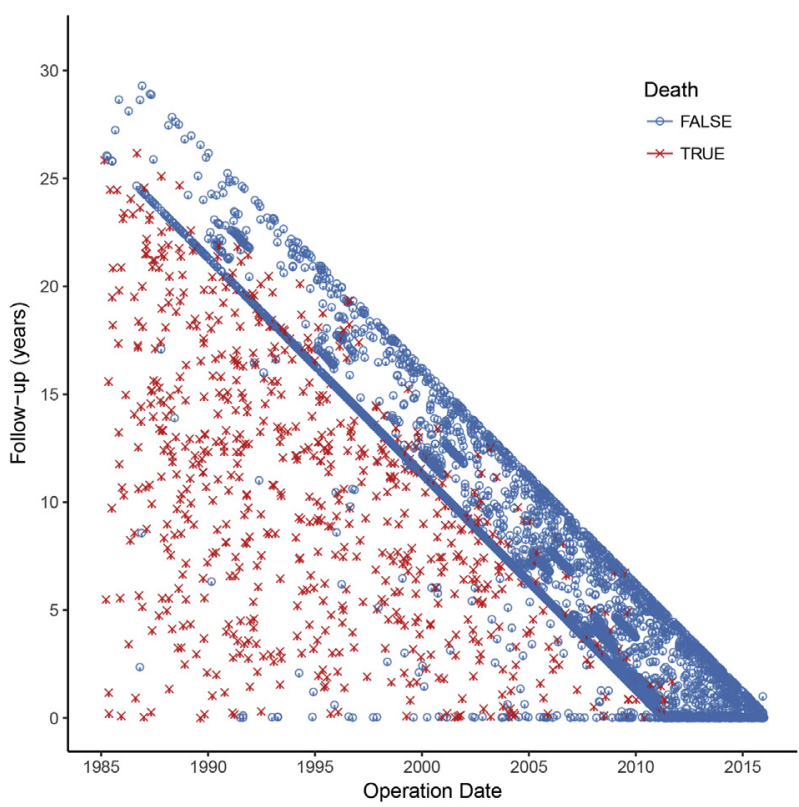

FIGURE E5. Goodness of follow-up over the study period. Patients are represented by blue circles. Nearly solid diagonal line represents those last updated at last systematic anniversary-type follow-up at 2 and 5 years and at 5 -year increments to 20 years.

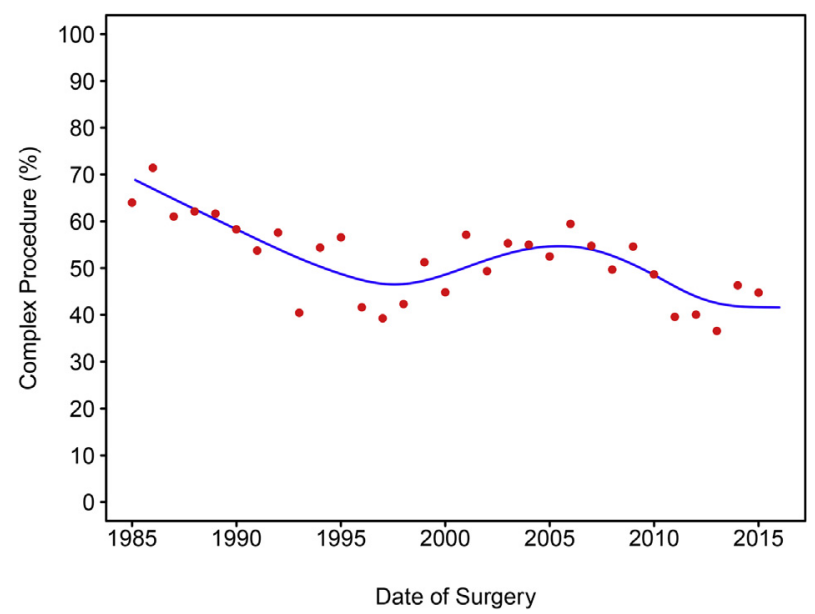

FIGURE E7. Temporal trend of complex mitral valve prolapse. Solid line is a smoothing spline curve, and filled circles represent percentage of patients with complex prolapse disease each year.
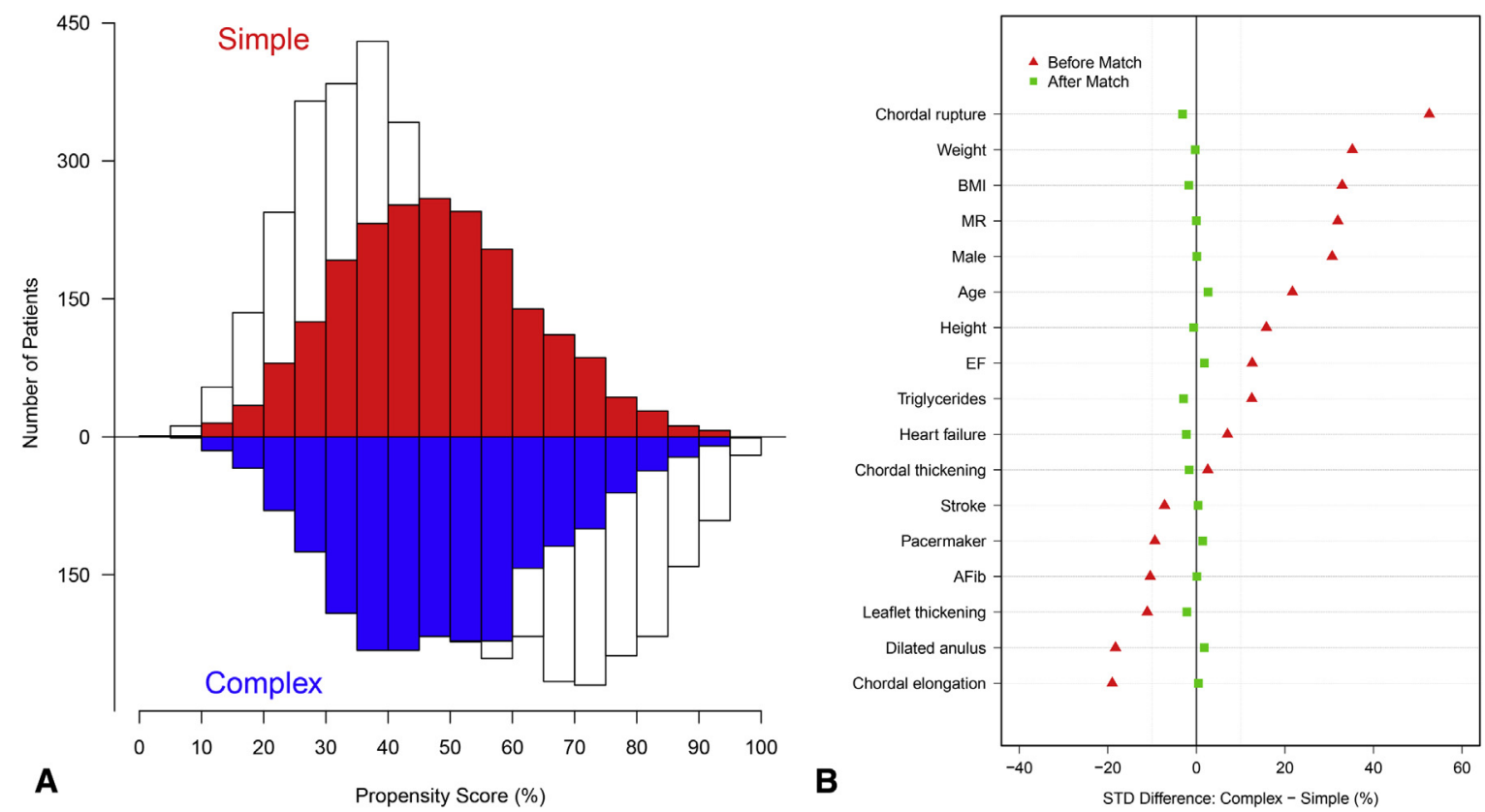

FIGURE E6. Quality of propensity matching of patients undergoing simple versus complex mitral valve repair. A, Mirrored histogram of distribution of propensity scores for simple and complex groups. Shaded areas represent 2065 matched patient pairs. Unshaded areas represent unmatched patients. B, Standardized difference of selected variables before and after matching, illustrating good matching. BMI, Body mass index; $M R$, mitral regurgitation; $E F$, ejection fraction; $A F i b$, atrial fibrillation; STD, standardized. 


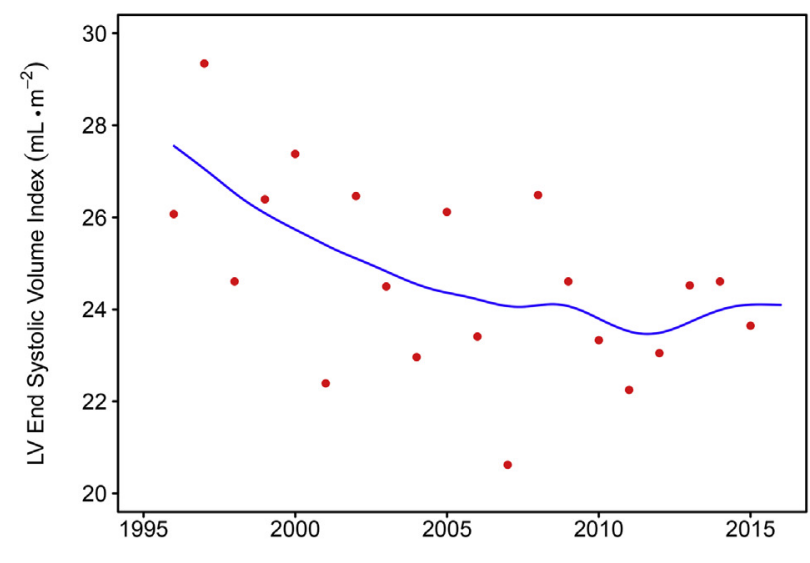

A

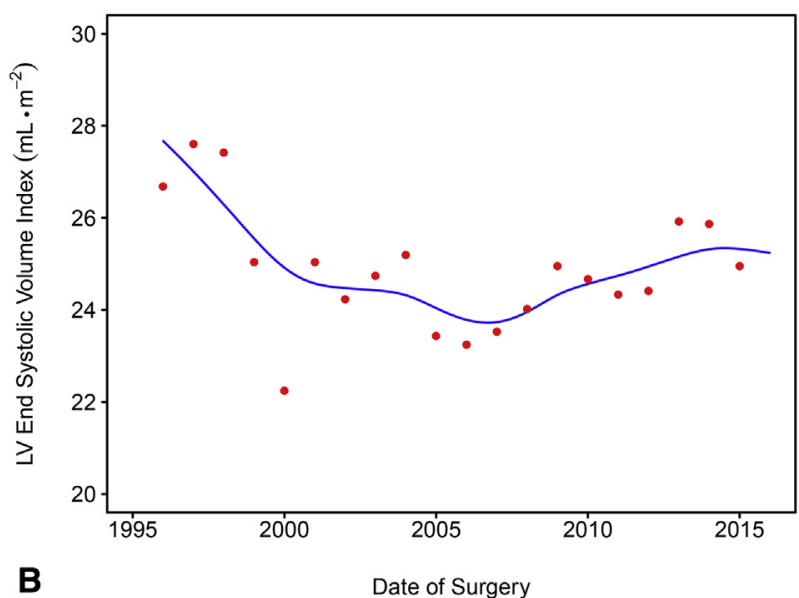

FIGURE E8. Temporal trend in left ventricle $(L V)$ end-systolic volume index among patients presenting with simple and complex mitral valve prolapse. Solid line is a smoothing spline curve, and filled circles represent mean values each year. A, Patients with simple disease. B, Patients with complex disease.
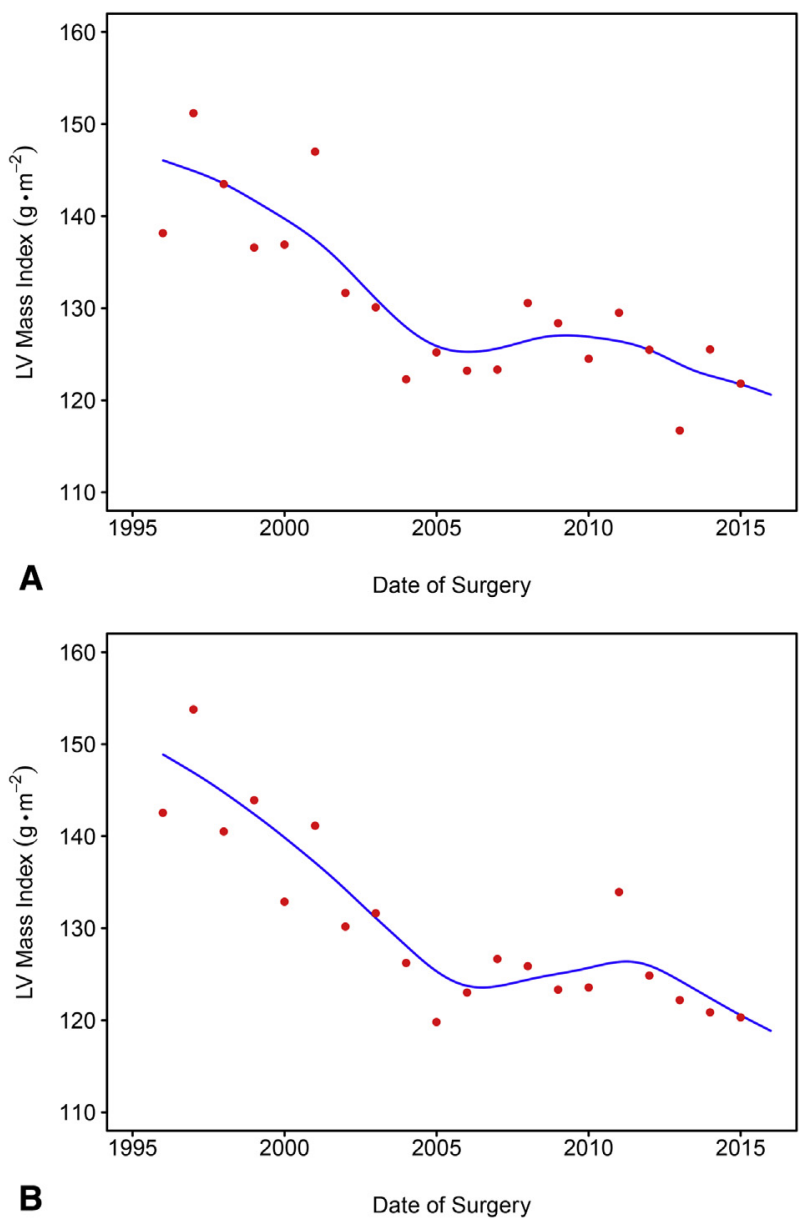

FIGURE E9. Temporal trend in left ventricular mass index among patients presenting with simple and complex mitral valve prolapse. Solid line is a smoothing spline curve, and filled circles represent mean values each year. A, Patients with simple disease. B, Patients with complex disease. $L V$, Left ventricular. 

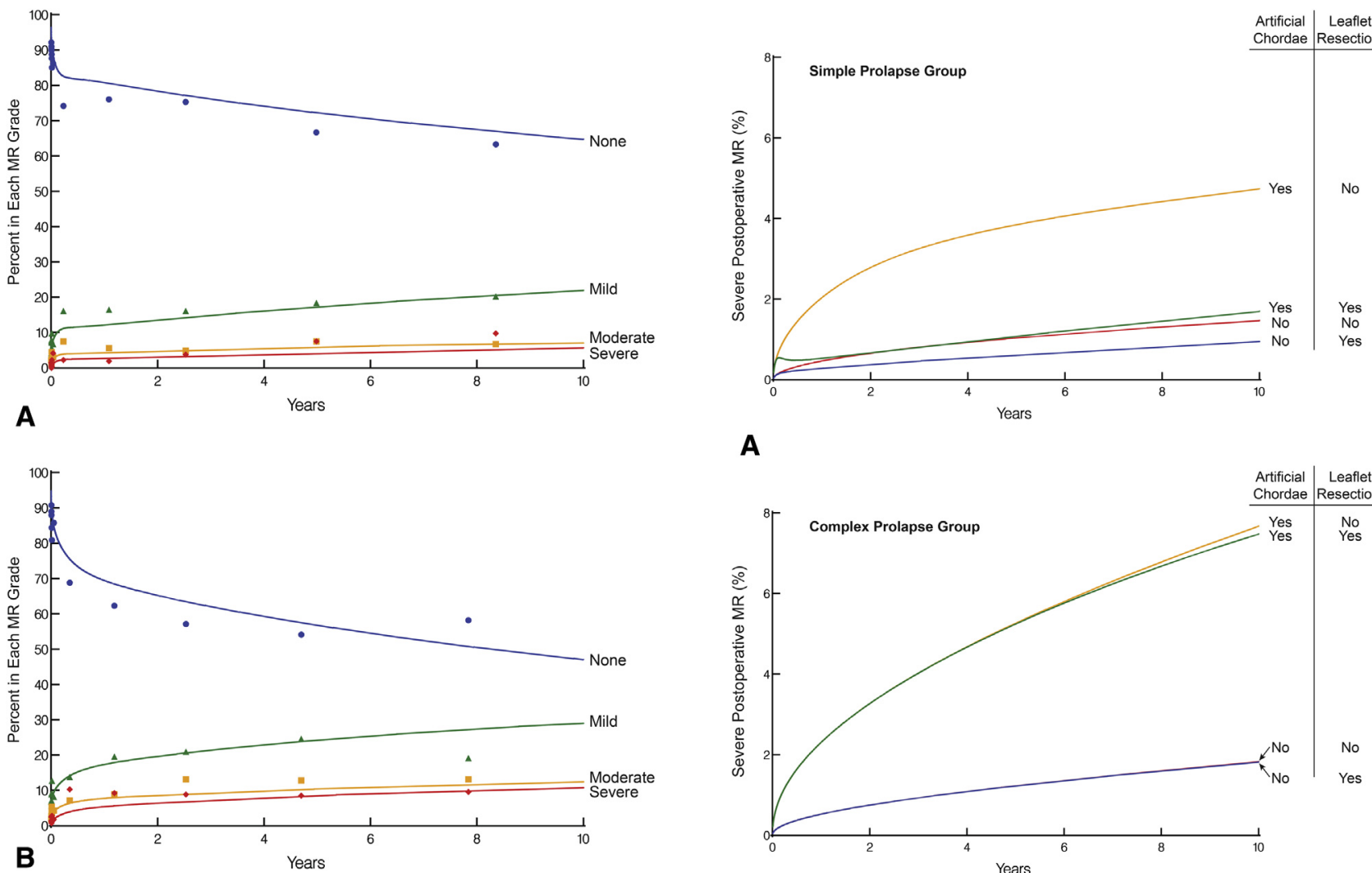

\section{A}

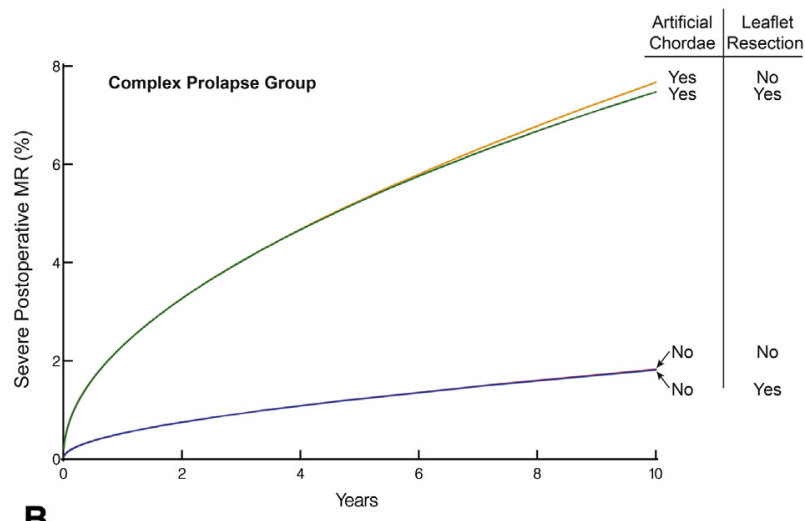

FIGURE E10. Temporal trend of severe postoperative mitral regurgitation $(M R)$ after mitral valve repair in propensity-matched patients. Solid lines represent parametric ensemble average of percentage of patients with severe postoperative MR. Symbols represent data grouped (without regard to repeated measurements) within time frames to provide a crude verification of model fit. No/trace MR is denoted by blue line and circles, mild $\mathrm{MR}$ is denoted by green line and triangles, moderate MR is denoted by $o r-$ ange line and squares, and severe MR is denoted by red line and diamonds. A, Matched patients with simple disease. B, Matched patients with complex disease.

IGURE E11. Temporal trend of severe postoperative mitral regurgitation $(M R)$ after mitral valve repair. Solid lines represent parametric ensemble average of percent of patients with severe postoperative MR. These nomograms are based on the multivariable equation in Table E8. Variables held constant are race other than black, no prior myocardial infarction, preoperative unscaled left atrial volume indexed by body surface area $29 \mathrm{~mL} / \mathrm{m}$, preoperative creatinine clearance (Cockcroft-Gault) $93 \mathrm{~mL} / \mathrm{min}$, preoperative right ventricular systolic pressure $40 \mathrm{~mm} \mathrm{Hg}$, and date of operation January 2005. A, Patients with simple disease. Preoperative right ventricular systolic pressure $40 \mathrm{~mm} \mathrm{Hg}$, and date of operation January 2005. B, Patients with complex disease. 


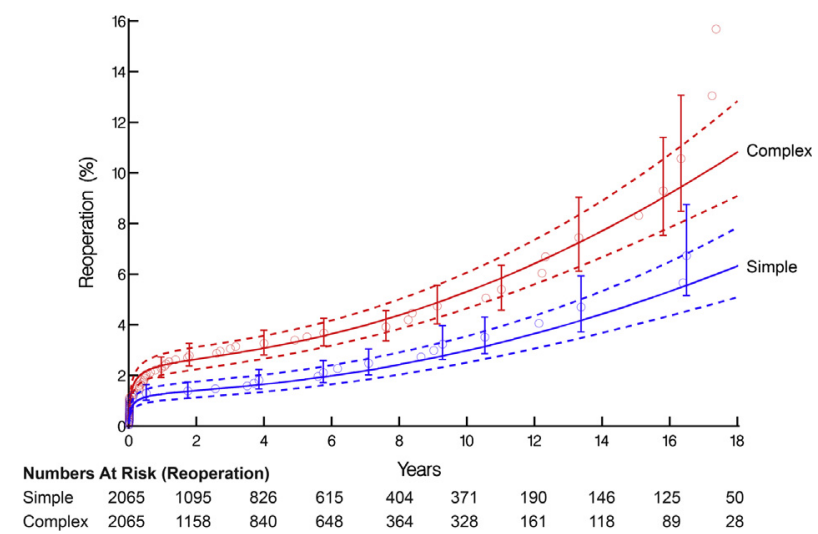

FIGURE E12. Reoperation after mitral valve repair in propensitymatched patients. Each symbol represents a reoperation positioned on the vertical axis by the Kaplan-Meier estimator; vertical bars are $68 \%$ confidence limits equivalent to \pm 1 standard error. Solid lines are parametric hazard estimates enclosed within a dashed $68 \%$ confidence band. Simple prolapse group is denoted by blue lines and circles and complex prolapse group is denoted by red lines and circles.

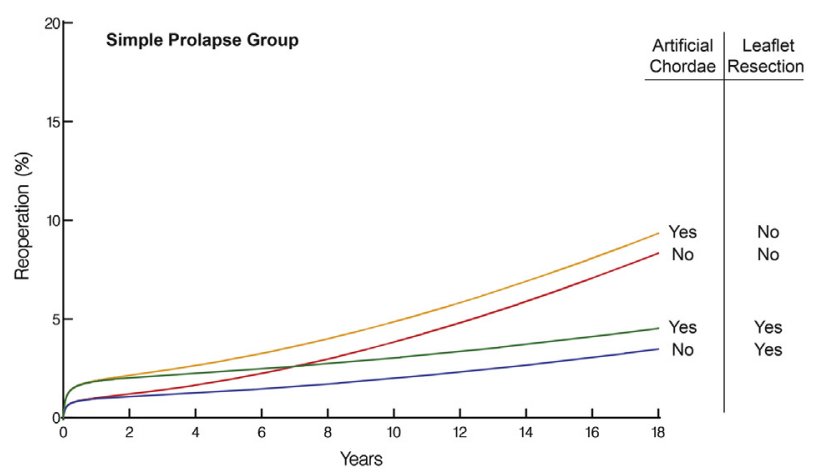

A

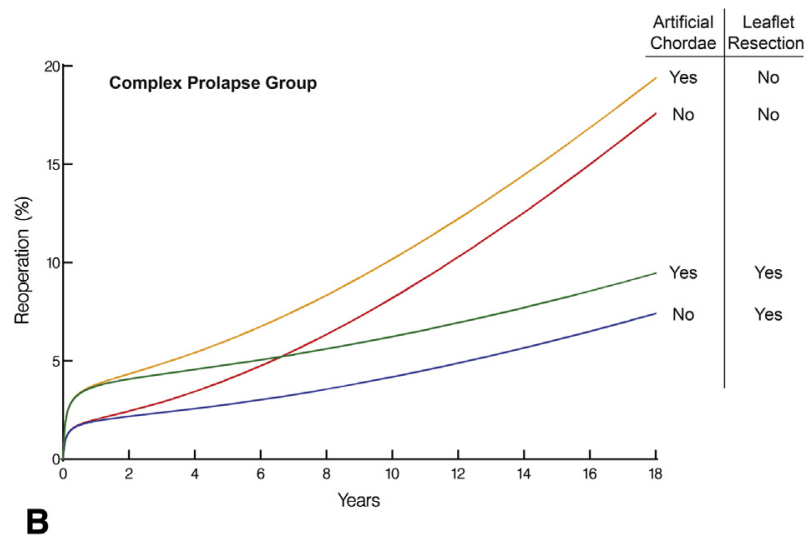

FIGURE E13. Reoperation after mitral valve repair. Solid lines are parametric hazard estimates. These nomograms are based on the multivariable equation in Table E9. Variables held constant are New York Heart Association functional class II, no prior myocardial infarction, no preoperative pulmonary valve regurgitation, preoperative unscaled left atrial volume indexed by body surface area $29 \mathrm{~mL} / \mathrm{m}$, preoperative blood urea nitrogen $18 \mathrm{mg} / \mathrm{dL}$, preoperative creatinine clearance (Cockcroft-Gault) $93 \mathrm{~mL} / \mathrm{min}$, preoperative hematocrit $41 \%$, annuloplasty, and date of operation January 2005. A, Patients with simple disease. B, Patients with complex disease. 
TABLE E1. Matched cohort with and without postoperative echocardiogram (postop echo)

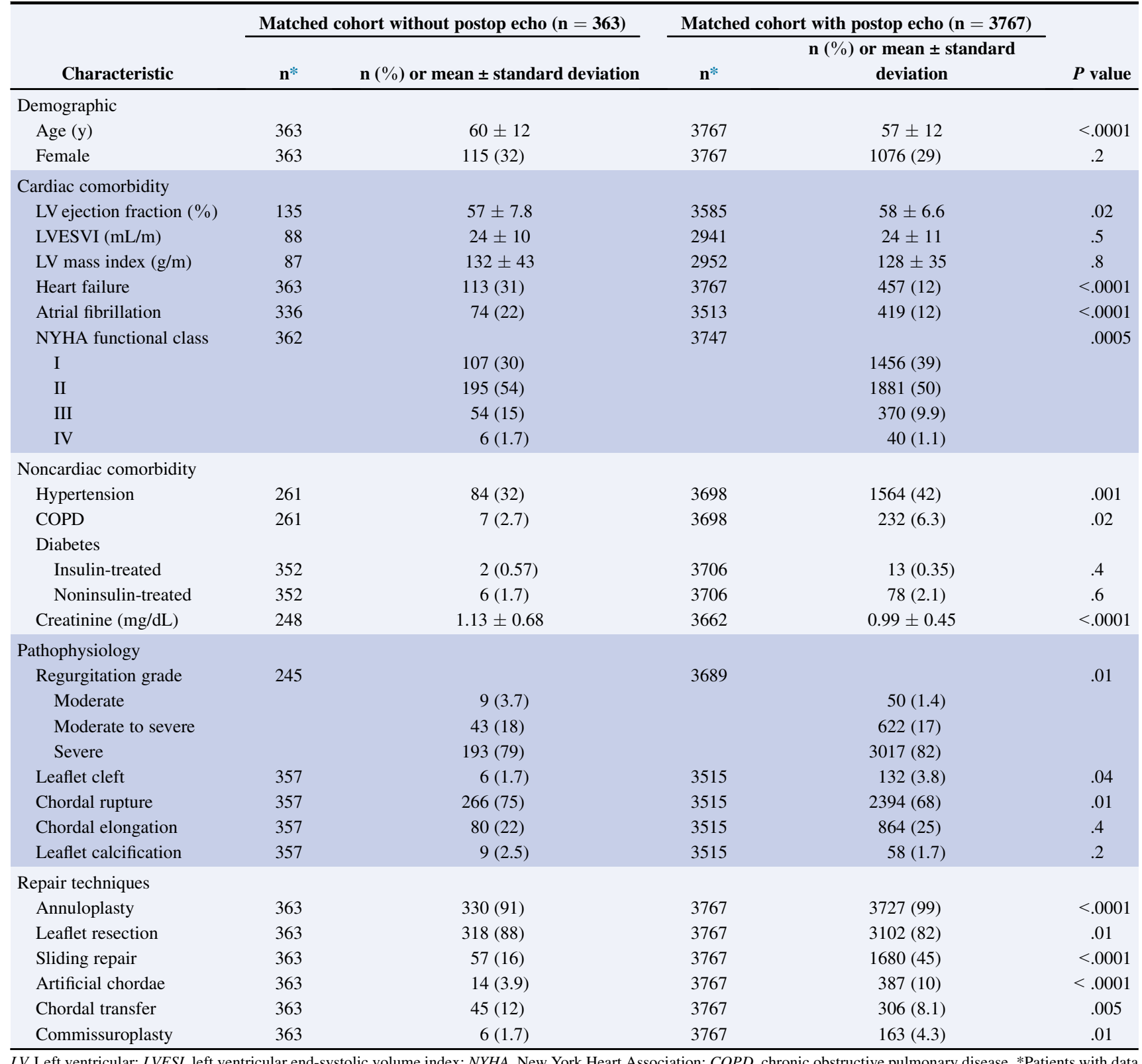

$L V$, Left ventricular; $L V E S I$, left ventricular end-systolic volume index; $N Y H A$, New York Heart Association; COPD, chronic obstructive pulmonary disease. *Patients with data available. 
TABLE E2. Matched cohort with and without routine Cleveland Clinic follow-up postdischarge echocardiogram (echo)

\begin{tabular}{|c|c|c|c|c|c|}
\hline \multirow[b]{3}{*}{ Characteristic } & \multicolumn{5}{|c|}{ Matched cohort without postdischarge echo $(n=2682)$ Matched cohort with postdischarge echo $(n=1085)$} \\
\hline & \multicolumn{3}{|c|}{ n $(\%)$ or mean \pm standard } & \multirow{2}{*}{$\begin{array}{c}\text { n }(\%) \text { or mean } \pm \text { standard } \\
\text { deviation }\end{array}$} & \multirow[b]{2}{*}{$P$ value } \\
\hline & n* & deviation & $\mathbf{n}^{*}$ & & \\
\hline \multicolumn{6}{|l|}{ Demographic } \\
\hline Age $(y)$ & 2682 & $57 \pm 12$ & 1085 & $58 \pm 11$ & .002 \\
\hline Female & 2682 & $748(28)$ & 1085 & $328(30)$ & .15 \\
\hline \multicolumn{6}{|l|}{ Cardiac comorbidity } \\
\hline LV ejection fraction $(\%)$ & 2639 & $59 \pm 6.5$ & 946 & $58 \pm 6.8$ & $<.0001$ \\
\hline LVESVI (mL/m) & 2253 & $24 \pm 11$ & 688 & $25 \pm 11$ & .02 \\
\hline LV mass index $(\mathrm{g} / \mathrm{m})$ & 2260 & $128 \pm 35$ & 692 & $129 \pm 34$ & .8 \\
\hline Heart failure & 2682 & $296(11)$ & 1085 & $161(15)$ & .001 \\
\hline Atrial fibrillation & 2546 & $272(11)$ & 967 & $147(15)$ & .0002 \\
\hline NYHA functional class & 2662 & & 1085 & & .002 \\
\hline I & & $1080(41)$ & & $376(35)$ & \\
\hline II & & $1312(49)$ & & $569(52)$ & \\
\hline III & & $241(9.1)$ & & $129(12)$ & \\
\hline IV & & $29(1.1)$ & & $11(1.0)$ & \\
\hline \multicolumn{6}{|l|}{ Noncardiac comorbidity } \\
\hline Hypertension & 2675 & $1114(42)$ & 1023 & $450(44)$ & .2 \\
\hline COPD & 2675 & $155(5.8)$ & 1023 & 77 (7.5) & .05 \\
\hline \multicolumn{6}{|l|}{ Diabetes } \\
\hline Insulin-treated & 2645 & $6(0.23)$ & 1061 & $7(0.66)$ & .04 \\
\hline Noninsulin-treated & 2645 & $47(1.8)$ & 1061 & $31(2.9)$ & .03 \\
\hline Creatinine $(\mathrm{mg} / \mathrm{dL})$ & 2654 & $0.97 \pm 0.36$ & 1008 & $1.02 \pm 0.63$ & .01 \\
\hline \multicolumn{6}{|l|}{ Pathophysiology } \\
\hline Regurgitation grade & 2673 & & 1016 & & .7 \\
\hline Moderate & & $39(1.5)$ & & $11(1.1)$ & \\
\hline Moderate to severe & & 448 (17) & & 174 (17) & \\
\hline Severe & & $2186(82)$ & & $831(82)$ & \\
\hline Leaflet cleft & 2471 & $99(4.0)$ & 1044 & $33(3.2)$ & .2 \\
\hline Chordal rupture & 2471 & $1660(67)$ & 1044 & $734(70)$ & .07 \\
\hline Chordal elongation & 2471 & $579(23)$ & 1044 & $285(27)$ & .02 \\
\hline Leaflet calcification & 2471 & $41(1.7)$ & 1044 & 17 (1.6) & $>.9$ \\
\hline \multicolumn{6}{|l|}{ Repair technique } \\
\hline Annuloplasty & 2682 & 2675 (100) & 1085 & 1052 (97) & $<.0001$ \\
\hline Leaflet resection & 2682 & $2224(83)$ & 1085 & $878(81)$ & .14 \\
\hline Sliding repair & 2682 & $1240(46)$ & 1085 & $440(41)$ & .002 \\
\hline Artificial chordae & 2682 & $261(9.7)$ & 1085 & $126(12)$ & .08 \\
\hline Chordal transfer & 2682 & $189(7.0)$ & 1085 & 117 (11) & .0001 \\
\hline Commissuroplasty & 2682 & $124(4.6)$ & 1085 & $39(3.6)$ & .16 \\
\hline
\end{tabular}
available. 
TABLE E3. Preoperative factors associated with simple and complex disease

\begin{tabular}{|c|c|c|c|}
\hline Factor & Estimate \pm standard error & $P$ value & Reliability $(\%)^{*}$ \\
\hline \multicolumn{4}{|l|}{ Simple disease } \\
\hline Male & $-0.19 \pm 0.070$ & .006 & 81 \\
\hline Older age $\dagger$ & $1.1 \pm 0.13$ & $<.0001$ & 100 \\
\hline Larger weight/height ratio $\ddagger$ & $-1.5 \pm 0.19$ & $<.0001$ & 100 \\
\hline Higher mitral valve regurgitation grade & $-0.49 \pm 0.076$ & $<.0001$ & 100 \\
\hline Chordal rupture & $-0.85 \pm 0.064$ & $<.0001$ & 100 \\
\hline Heart failure & $-0.30 \pm 0.082$ & .0003 & 73 \\
\hline Higher ejection fraction $(\%) \S$ & $-0.22 \pm 0.099$ & .02 & 70 \\
\hline Higher triglycerides (mg/dL) & $-0.0010 \pm 0.00045$ & .02 & 79 \\
\hline Earlier time to index operation $\|$ & $-0.23 \pm 0.057$ & $<.0001$ & 99 \\
\hline \multicolumn{4}{|l|}{ Complex disease } \\
\hline Higher TV regurgitation grade & $0.11 \pm 0.037$ & .004 & 99 \\
\hline \multicolumn{4}{|l|}{ Mitral valve pathology } \\
\hline Chordal elongation & $0.34 \pm 0.065$ & $<.0001$ & 100 \\
\hline Dilated annulus & $0.40 \pm 0.082$ & $<.0001$ & 100 \\
\hline Leaflet thickening & $0.36 \pm 0.082$ & $<.0001$ & 94 \\
\hline Atrial fibrillation & $0.30 \pm 0.087$ & .0005 & 87 \\
\hline Complete heart block & $0.92 \pm 0.36$ & .01 & 77 \\
\hline Stroke & $0.51 \pm 0.21$ & .02 & 73 \\
\hline
\end{tabular}

$T V$, Tricuspid valve. *Percent of times factor appeared in 1000 bootstrap models. $\dagger(50 /$ age), inverse transformation. $\ddagger$ Ln(weight/height ratio), natural logarithmic transformation. $\S(\text { Ejection fraction/50) })^{2}$, squared transformation. $\| \operatorname{Ln}($ time to index operation), natural logarithmic transformation.

TABLE E4. Patient characteristics: Propensity matched

\begin{tabular}{|c|c|c|c|c|c|}
\hline \multirow[b]{2}{*}{ Characteristic } & \multicolumn{2}{|c|}{ Simple disease $(n=2065)$} & \multicolumn{2}{|c|}{ Complex disease $(n=2065)$} & \multirow[b]{2}{*}{$P$ value } \\
\hline & $\mathbf{n}^{*}$ & $\begin{array}{c}\text { n }(\%) \text { or mean } \pm \text { standard } \\
\text { deviation }\end{array}$ & $\mathbf{n}^{*}$ & $\begin{array}{c}\text { n }(\%) \text { or mean } \pm \text { standard } \\
\text { deviation }\end{array}$ & \\
\hline \multicolumn{6}{|l|}{ Demographic } \\
\hline Age (y) & 2065 & $58 \pm 12$ & 2065 & $57 \pm 12$ & .4 \\
\hline Female & 2065 & $595(29)$ & 2065 & $596(29)$ & $>.9$ \\
\hline \multicolumn{6}{|l|}{ Cardiac comorbidity } \\
\hline LV ejection fraction $(\%)$ & 1860 & $58 \pm 6.6$ & 1860 & $58 \pm 6.6$ & .5 \\
\hline LVESVI (mL/m) & 1507 & $24 \pm 11$ & 1522 & $24 \pm 11$ & 6 \\
\hline LV mass index $(\mathrm{g} / \mathrm{m})$ & 1519 & $128 \pm 34$ & 1520 & $129 \pm 36$ & .7 \\
\hline Heart failure & 2065 & $277(13)$ & 2065 & $293(14)$ & .5 \\
\hline Atrial fibrillation & 1918 & $246(13)$ & 1931 & $247(13)$ & $>.9$ \\
\hline NYHA functional class & 2051 & & 2058 & & .6 \\
\hline I & & $781(38)$ & & $782(38)$ & \\
\hline II & & $1047(51)$ & & $1029(50)$ & \\
\hline III & & $199(9.7)$ & & $225(11)$ & \\
\hline IV & & $24(1.2)$ & & $22(1.1)$ & \\
\hline \multicolumn{6}{|l|}{ Noncardiac comorbidity } \\
\hline Hypertension & 1989 & $823(41)$ & 1970 & $825(42)$ & .8 \\
\hline COPD & 1989 & $132(6.6)$ & 1970 & $107(5.4)$ & .11 \\
\hline \multicolumn{6}{|l|}{ Diabetes } \\
\hline Insulin-treated & 2034 & $8(0.39)$ & 2024 & $7(0.35)$ & .8 \\
\hline Noninsulin-treated & 2034 & $43(2.1)$ & 2024 & $41(2.0)$ & .8 \\
\hline Creatinine (mg/dL) & 1966 & $1.0 \pm 0.48$ & 1944 & $0.99 \pm 0.46$ & .7 \\
\hline
\end{tabular}

$L V$, Left ventricle; $L V E S V I$, left ventricular end-systolic volume index; $N Y H A$, New York Heart Association; COPD, chronic obstructive pulmonary disease. *Patients with data available. 
TABLE E5. Mitral valve pathophysiology and repair techniques: Propensity matched

\begin{tabular}{|c|c|c|c|c|c|}
\hline \multirow[b]{2}{*}{ Characteristic } & \multicolumn{2}{|c|}{ Simple disease $(n=2065)$} & \multicolumn{2}{|c|}{ Complex disease $(n=2065)$} & \multirow[b]{2}{*}{$P$ value } \\
\hline & $\mathbf{n}^{*}$ & n $(\%)$ & $\mathbf{n}^{*}$ & n $(\%)$ & \\
\hline \multicolumn{6}{|l|}{ Pathophysiology } \\
\hline Regurgitation grade & 1976 & & 1958 & & .5 \\
\hline Moderate & & $33(1.7)$ & & $26(1.3)$ & \\
\hline Moderate to severe & & $323(16)$ & & 342 (17) & \\
\hline Severe & & $1620(82)$ & & $1590(81)$ & \\
\hline Leaflet cleft & 1936 & $65(3.4)$ & 1936 & $73(3.8)$ & .5 \\
\hline Dilated annulus & 1936 & $275(14)$ & 1936 & $263(14)$ & .6 \\
\hline Chordal rupture & 1936 & $1316(68)$ & 1936 & $1344(69)$ & .3 \\
\hline Chordal elongation & 1936 & $474(24)$ & 1936 & $470(24)$ & .9 \\
\hline Leaflet calcification & 1936 & $36(1.9)$ & 1936 & $31(1.6)$ & .5 \\
\hline \multicolumn{6}{|c|}{$\begin{array}{l}\text { Repair techniques that were } \\
\text { not included in } \\
\text { propensity analysis }\end{array}$} \\
\hline Annuloplasty & 2065 & $2030(98)$ & 2065 & 2027 (98) & .7 \\
\hline Leaflet resection & 2065 & $1849(90)$ & 2065 & $1571(76)$ & $<.0001$ \\
\hline Sliding repair & 2065 & 803 (39) & 2065 & $934(45)$ & $<.0001$ \\
\hline Artificial chordae & 2065 & $118(5.7)$ & 2065 & $283(14)$ & $<.0001$ \\
\hline Chordal transfer & 2065 & $44(2.1)$ & 2065 & 307 (15) & $<.0001$ \\
\hline Commissuroplasty & 2065 & $50(2.4)$ & 2065 & $119(5.8)$ & $<.0001$ \\
\hline \multicolumn{6}{|l|}{ Incision characteristic } \\
\hline Full sternotomy & 2023 & $711(35)$ & 2031 & $810(40)$ & $<.0001$ \\
\hline Thoracotomy & 2023 & $232(11)$ & 2031 & $225(11)$ & $<.0001$ \\
\hline Partial sternotomy & 2023 & $691(34)$ & 2031 & $680(33)$ & $<.0001$ \\
\hline Robotic & 2023 & 3899 (19) & 2031 & $316(16)$ & $<.0001$ \\
\hline
\end{tabular}

*Patients with data available. 
TABLE E6. Simple degenerative mitral valve disease: Unmatched versus propensity matched

\begin{tabular}{|c|c|c|c|c|c|}
\hline \multirow[b]{2}{*}{ Characteristic } & \multicolumn{2}{|c|}{ Simple disease unmatched $(n=1036)$} & \multicolumn{2}{|c|}{ Simple disease matched $(n=2065)$} & \multirow[b]{2}{*}{$P$ value } \\
\hline & $\mathbf{n}^{*}$ & $\begin{array}{c}\text { n }(\%) \text { or mean } \pm \text { standard } \\
\text { deviation }\end{array}$ & $\mathbf{n}^{*}$ & $\begin{array}{c}\text { n }(\%) \text { or mean } \pm \text { standard } \\
\text { deviation }\end{array}$ & \\
\hline \multicolumn{6}{|l|}{ Demographic } \\
\hline Age (y) & 1036 & $60 \pm 10$ & 2065 & $58 \pm 12$ & $<.0001$ \\
\hline Female & 1036 & 149 (14) & 2065 & $595(29)$ & $<.0001$ \\
\hline \multicolumn{6}{|l|}{ Cardiac comorbidity } \\
\hline LV ejection fraction $(\%)$ & 950 & $59 \pm 6.4$ & 1860 & $58 \pm 6.6$ & .01 \\
\hline LVESVI $(\mathrm{mL} / \mathrm{m})$ & 775 & $25 \pm 12$ & 1507 & $24 \pm 11$ & .4 \\
\hline LV mass index $(\mathrm{g} / \mathrm{m})$ & 778 & $128 \pm 39$ & 1519 & $128 \pm 34$ & .7 \\
\hline Heart failure & 1035 & $222(21)$ & 2065 & $277(13)$ & $<.0001$ \\
\hline Atrial fibrillation & 984 & $96(9.8)$ & 1918 & $246(13)$ & .02 \\
\hline NYHA functional class & 1029 & & 2051 & & .3 \\
\hline I & & $380(37)$ & & $781(38)$ & \\
\hline II & & $519(50)$ & & $1047(51)$ & \\
\hline III & & $111(11)$ & & $199(9.7)$ & \\
\hline IV & & $19(1.8)$ & & $24(1.2)$ & \\
\hline \multicolumn{6}{|l|}{ Noncardiac comorbidity } \\
\hline Hypertension & 1014 & $582(57)$ & 1989 & $823(41)$ & $<.0001$ \\
\hline COPD & 1013 & $43(4.2)$ & 1989 & $132(6.6)$ & .008 \\
\hline \multicolumn{6}{|l|}{ Diabetes } \\
\hline Insulin-treated & 1021 & $5(0.49)$ & 2034 & $8(0.39)$ & .8 \\
\hline Noninsulin-treated & 1021 & $46(4.5)$ & 2034 & $43(2.1)$ & .0002 \\
\hline Creatinine (mg/dL) & 1005 & $1.0 \pm 0.41$ & 1966 & $1.0 \pm 0.48$ & $<.0001$ \\
\hline \multicolumn{6}{|l|}{ Pathophysiology } \\
\hline Regurgitation grade & 1003 & & 1976 & & $<.0001$ \\
\hline Moderate & & $4(0.40)$ & & $33(1.7)$ & \\
\hline Moderate to severe & & $70(7.0)$ & & $323(16)$ & \\
\hline Severe & & $929(93)$ & & $1620(82)$ & \\
\hline Leaflet cleft & 948 & $28(3.0)$ & 1936 & $65(3.4)$ & 6 \\
\hline Chordal rupture & 948 & $909(96)$ & 1936 & $1316(68)$ & $<.0001$ \\
\hline Chordal elongation & 948 & $140(15)$ & 1936 & $474(24)$ & $<.0001$ \\
\hline Leaflet calcification & 948 & $4(0.42)$ & 1936 & $36(1.9)$ & .001 \\
\hline \multicolumn{6}{|l|}{ Repair technique } \\
\hline Annuloplasty & 1036 & 1025 (99) & 2065 & $2030(98)$ & .17 \\
\hline Leaflet resection & 1036 & $954(92)$ & 2065 & $1849(90)$ & .02 \\
\hline Sliding repair & 1036 & $396(38)$ & 2065 & 803 (39) & .7 \\
\hline Artificial chordae & 1036 & $62(6.0)$ & 2065 & $118(5.7)$ & .8 \\
\hline Chordal transfer & 1036 & $15(1.4)$ & 2065 & $44(2.1)$ & .19 \\
\hline Commissuroplasty & 1036 & $26(2.5)$ & 2065 & $50(2.4)$ & .9 \\
\hline \multicolumn{6}{|l|}{ Complication } \\
\hline Death & 1036 & $0(0)$ & 2065 & $1(0.048)$ & $>.9$ \\
\hline Respiratory complication & 768 & $13(1.7)$ & 1383 & $19(1.4)$ & 6 \\
\hline Sternal wound infection & 1036 & $7(0.68)$ & 2065 & $5(0.24)$ & .12 \\
\hline Reoperation for bleeding & 1036 & $23(2.2)$ & 2065 & $45(2.2)$ & .9 \\
\hline Atrial fibrillation & 906 & $311(34)$ & 1724 & $491(28)$ & .002 \\
\hline Renal failure & 901 & $1(0.11)$ & 1729 & $1(0.058)$ & $>.9$ \\
\hline Stroke & 1036 & $12(1.2)$ & 2065 & $18(0.087)$ & .4 \\
\hline
\end{tabular}

$\overline{L V}$, Left ventricle; $L V E S I$, left ventricular end-systolic volume index; NYHA, New York Heart Association; COPD, chronic obstructive pulmonary disease. *Patients with data available. 
TABLE E7. Complex degenerative mitral valve disease: Unmatched versus propensity matched

\begin{tabular}{|c|c|c|c|c|c|}
\hline \multirow[b]{2}{*}{ Characteristic } & \multicolumn{2}{|c|}{ Complex disease unmatched $(n=987)$} & \multicolumn{2}{|c|}{ Complex disease matched $(n=2065)$} & \multirow[b]{2}{*}{$P$ value } \\
\hline & $\overline{\mathbf{n}^{*}}$ & n $(\%)$ or mean \pm standard deviation & $\mathbf{n}^{*}$ & n $(\%)$ or mean \pm standard deviation & \\
\hline \multicolumn{6}{|l|}{ Demographic } \\
\hline Age (y) & 987 & $53 \pm 14$ & 2065 & $57 \pm 12$ & $<.0001$ \\
\hline Female & 987 & $564(57)$ & 2065 & $596(29)$ & $<.0001$ \\
\hline \multicolumn{6}{|l|}{ Cardiac comorbidity } \\
\hline LV ejection fraction $(\%)$ & 791 & $57 \pm 6.5$ & 1860 & $58 \pm 6.6$ & $<.0001$ \\
\hline LVESVI (mL/m) & 640 & $25 \pm 12$ & 1522 & $24 \pm 11$ & .12 \\
\hline LV mass index $(\mathrm{g} / \mathrm{m})$ & 637 & $125 \pm 33$ & 1520 & $129 \pm 36$ & .08 \\
\hline Heart failure & 987 & $122(12)$ & 2065 & $293(14)$ & .17 \\
\hline Atrial fibrillation & 911 & $189(21)$ & 1931 & $247(13)$ & $<.0001$ \\
\hline NYHA functional class & 983 & & 2058 & & .3 \\
\hline I & & $339(34)$ & & $782(38)$ & \\
\hline II & & $515(52)$ & & $1029(50)$ & \\
\hline III & & $118(12)$ & & $225(11)$ & \\
\hline IV & & $11(1.1)$ & & $22(1.1)$ & \\
\hline \multicolumn{6}{|l|}{ Noncardiac comorbidity } \\
\hline Hypertension & 914 & 243 (27) & 1970 & $825(42)$ & $<.0001$ \\
\hline COPD & 914 & $69(7.5)$ & 1970 & $107(5.4)$ & .03 \\
\hline \multicolumn{6}{|l|}{ Diabetes } \\
\hline Insulin-treated & 973 & $2(0.21)$ & 2024 & $7(0.35)$ & .7 \\
\hline Noninsulin-treated & 973 & $9(0.92)$ & 2024 & $41(2.0)$ & .03 \\
\hline Creatinine $(\mathrm{mg} / \mathrm{dL})$ & 898 & $0.96 \pm 0.75$ & 1944 & $0.99 \pm 0.46$ & $<.0001$ \\
\hline \multicolumn{6}{|l|}{ Pathophysiology } \\
\hline Regurgitation grade & 891 & & 1958 & & $<.0001$ \\
\hline Moderate & & $63(7.1)$ & & $26(1.3)$ & \\
\hline Moderate to severe & & $367(41)$ & & 342 (17) & \\
\hline Severe & & $461(52)$ & & $1590(81)$ & \\
\hline Leaflet cleft & 940 & $38(4.0)$ & 1936 & $73(3.8)$ & .7 \\
\hline Chordal rupture & 940 & 177 (19) & 1936 & $1344(69)$ & $<.0001$ \\
\hline Chordal elongation & 940 & $379(40)$ & 1936 & $470(24)$ & $<.0001$ \\
\hline Leaflet calcification & 940 & $32(3.4)$ & 1936 & 31 (1.6) & .002 \\
\hline \multicolumn{6}{|l|}{ Repair techniques } \\
\hline Annuloplasty & 987 & $973(99)$ & 2065 & $2027(98)$ & .4 \\
\hline Leaflet resection & 987 & $678(69)$ & 2065 & $1571(76)$ & .0001 \\
\hline Sliding repair & 987 & $443(45)$ & 2065 & $934(45)$ & .9 \\
\hline Artificial chordae & 987 & $116(12)$ & 2065 & $283(14)$ & .13 \\
\hline Chordal transfer & 987 & $163(17)$ & 2065 & $307(15)$ & .2 \\
\hline Commissuroplasty & 987 & $59(6.0)$ & 2065 & $119(5.8)$ & .8 \\
\hline \multicolumn{6}{|l|}{ Complication } \\
\hline Death & 987 & $1(0.10)$ & 2065 & $2(0.10)$ & $>.9$ \\
\hline Respiratory complication & 602 & $14(2.3)$ & 1443 & $34(2.4)$ & $>.9$ \\
\hline Sternal wound infection & 987 & $3(0.30)$ & 2065 & $7(0.34)$ & $>.9$ \\
\hline Reoperation for bleeding & 987 & $33(3.3)$ & 2065 & $56(2.7)$ & .3 \\
\hline Atrial fibrillation & 738 & $192(26)$ & 1717 & $491(29)$ & .19 \\
\hline Renal failure & 739 & $2(0.27)$ & 1749 & $3(0.17)$ & .6 \\
\hline Stroke & 987 & $9(0.91)$ & 2065 & $28(1.4)$ & .3 \\
\hline
\end{tabular}

$L V$, Left ventricle; $L V E S I$, left ventricular end-systolic volume index; NYHA, New York Heart Association; COPD, chronic obstructive pulmonary disease. *Patients with data available. 
TABLE E8. Incremental risk factors for progression of mitral valve regurgitation $(n=6153)$

\begin{tabular}{|c|c|c|c|}
\hline Factor & Coefficient \pm standard error & $P$ value & Reliability $(\%) *$ \\
\hline \multicolumn{4}{|l|}{ Early phase } \\
\hline Black race & $0.94 \pm 0.37$ & .01 & 77 \\
\hline Prior myocardial infarction & $0.86 \pm 0.32$ & .006 & 97 \\
\hline Lower preoperative creatinine clearance (Cockcroft-Gault) $\dagger$ & $-0.80 \pm 0.21$ & .0002 & 78 \\
\hline Higher preoperative RV systolic pressure $\ddagger$ & $0.75 \pm 0.22$ & .001 & 100 \\
\hline Higher preoperative unscaled LA volume index $\ddagger$ & $0.58 \pm 0.15$ & .0002 & 88 \\
\hline Complex prolapse & $0.12 \pm 0.14$ & .4 & 100 \\
\hline Placement of artificial chordae & $1.5 \pm 0.19$ & $<.0001$ & 100 \\
\hline Earlier date of operation & $-1.8 \pm 0.15$ & $<.0001$ & 100 \\
\hline \multicolumn{4}{|l|}{ Late phase } \\
\hline Complex prolapse & $4.6 \pm 0.55$ & $<.0001$ & 100 \\
\hline No leaflet resection & $-3.0 \pm 1.2$ & .004 & 97 \\
\hline
\end{tabular}

$R V$, Right ventricle; $L A$, left atrium. *Percent of times factor appeared in 1000 bootstrap models. †Creatinine clearance/90, scaled transformation. $\ddagger$ Natural logarithmic transformation.

TABLE E9. Incremental risk factors for reoperation $(n=6153)$

\begin{tabular}{|c|c|c|c|}
\hline Factor & Coefficient \pm standard error & $P$ value & Reliability $(\%) *$ \\
\hline \multicolumn{4}{|l|}{ Early phase } \\
\hline Complex prolapse & $0.70 \pm 0.25$ & .004 & 69 \\
\hline Higher preoperative NYHA class & $0.35 \pm 0.15$ & .02 & 52 \\
\hline Preoperative unscaled LA volume index $\dagger$ & $0.45 \pm 0.22$ & .04 & 66 \\
\hline Higher preoperative creatinine clearance (Cockcroft-Gault) $\ddagger$ & $0.60 \pm 0.20$ & .003 & 86 \\
\hline Lower preoperative hematocrit $\S$ & $-2.7 \pm 0.93$ & .004 & 66 \\
\hline Earlier date of operation $\|$ & $-0.39 \pm 0.15$ & .01 & 79 \\
\hline Placement of artificial chordae & $0.78 \pm 0.39$ & .05 & 89 \\
\hline \multicolumn{4}{|l|}{ Late phase } \\
\hline Complex prolapse & $0.78 \pm 0.31$ & .01 & 83 \\
\hline Prior myocardial infarction & $1.4 \pm 0.41$ & .0009 & 72 \\
\hline Preoperative pulmonary valve regurgitation & $1.3 \pm 0.30$ & $<.0001$ & 87 \\
\hline No history of smoking & $-0.76 \pm 0.32$ & .02 & 58 \\
\hline Higher preoperative BUN & $0.84 \pm 0.36$ & .02 & 60 \\
\hline Annuloplasty & $-2.1 \pm 0.32$ & $<.0001$ & 96 \\
\hline No leaflet resection & $-1.2 \pm 0.31$ & .0002 & 56 \\
\hline
\end{tabular}

NYHA, New York Heart Association; $L A$, left atrium; $B U N$, blood urea nitrogen. *Percent of times factor appeared in 1000 bootstrap models. $\dagger$ Natural logarithmic transformation.

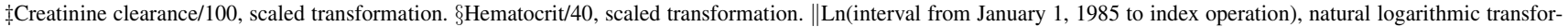
mation. $\uparrow \mathrm{BUN} / 20$, scaled transformation. 
TABLE E10. Incremental risk factors for death $(n=6153)$

\begin{tabular}{|c|c|c|c|}
\hline Factor & Coefficient \pm standard error & $P$ value & Reliability $(\%)^{*}$ \\
\hline \multicolumn{4}{|l|}{ Constant phase } \\
\hline Complex prolapse & $0.058 \pm 0.13$ & .6 & 19 \\
\hline Older age $\dagger$ & $1.2 \pm 0.073$ & $<.0001$ & 100 \\
\hline Lower LV ejection fraction $\ddagger$ & $-0.99 \pm 0.39$ & .01 & 91 \\
\hline Heart failure & $0.28 \pm 0.12$ & .02 & 78 \\
\hline Prior stroke & $0.67 \pm 0.20$ & .0009 & 68 \\
\hline Higher preoperative BUN & $0.018 \pm 0.0087$ & .04 & 95 \\
\hline Earlier date of operation & $-0.046 \pm 0.0092$ & $<.0001$ & 90 \\
\hline \multicolumn{4}{|l|}{ Late phase } \\
\hline Complex prolapse & $-0.15 \pm 0.21$ & .5 & 14 \\
\hline Higher preoperative body mass index $\ddagger$ & $2.2 \pm 0.62$ & .0003 & 68 \\
\hline Prior myocardial infarction & $1.0 \pm 0.28$ & .0004 & 67 \\
\hline Higher preoperative tricuspid valve regurgitation grade & $0.42 \pm 0.11$ & .0002 & 60 \\
\hline Preoperative pulmonary valve regurgitation & $0.85 \pm 0.21$ & $<.0001$ & 72 \\
\hline Carotid disease & $1.0 \pm 0.36$ & .005 & 64 \\
\hline Lower preoperative creatinine clearance (Cockcroft-Gault) & $-0.026 \pm 0.0036$ & $<.0001$ & 51 \\
\hline
\end{tabular}

$L V$, Left ventricle; $B U N$, blood urea nitrogen. *Percent of times factor appeared in 1000 bootstrap models. †Exponential transformation. †़Natural logarithmic transformation. 